\title{
Research Progress, Challenges, and Breakthroughs of Organoids as Disease Models
}

\author{
Yisheng Huang ${ }^{1 \dagger}$, Zhijie Huang ${ }^{1 \dagger}$, Zhengming Tang ${ }^{1}$, Yuanxin Chen ${ }^{1}$, Mingshu Huang ${ }^{1}$, \\ Hongyu Liu ${ }^{1}$, Weibo Huang ${ }^{2}$, Qingsong $\mathrm{Ye}^{3,4 *}$ and Bo Jia ${ }^{1 *}$ \\ ${ }^{1}$ Department of Oral Surgery, Stomatological Hospital, Southern Medical University, Guangzhou, China, ${ }^{2}$ Department of \\ stomatology, Guangdong Provincial Corps Hospital, Chinese People's Armed Police Force, Guangzhou, China, ${ }^{3}$ Center of \\ Regenerative Medicine, Renmin Hospital of Wuhan University, Wuhan University, Wuhan, China, ${ }^{4}$ School of Stomatology and \\ Medicine, Foshan University, Foshan, China
}

OPEN ACCESS

Edited by:

Tao Tan,

Kunming University of Science and

Technology, China

Reviewed by:

Debanjan Sarkar

University at Buffalo, United States

Michael Wagels,

Queensland Health, Australia

*Correspondence:

Qingsong Ye

qingsongye@hotmail.com

Bo Jia

dentist-jia@163.com

these authors have contributed equally to this work

Specialty section: This article was submitted to

Stem Cell Research,

a section of the journal

Frontiers in Cell and Developmental

Biology

Received: 13 July 2021 Accepted: 28 October 2021 Published: 16 November 2021

Citation:

Huang $Y$, Huang $Z$, Tang $Z$, Chen $Y$,

Huang $M$, Liu H, Huang W, Ye Q and Jia $B$ (2021) Research Progress,

Challenges, and Breakthroughs of Organoids as Disease Models. Front. Cell Dev. Biol. 9:740574. doi: 10.3389/fcell.2021.740574
Traditional cell lines and xenograft models have been widely recognized and used in research. As a new research model, organoids have made significant progress and development in the past 10 years. Compared with traditional models, organoids have more advantages and have been applied in cancer research, genetic diseases, infectious diseases, and regenerative medicine. This review presented the advantages and disadvantages of organoids in physiological development, pathological mechanism, drug screening, and organ transplantation. Further, this review summarized the current situation of vascularization, immune microenvironment, and hydrogel, which are the main influencing factors of organoids, and pointed out the future directions of development.

Keywords: organoids, disease model, vascularization, immune environment, extracellular matrix

\section{INTRODUCTION}

Organoids are a three-dimensional (3D) cell culture derived from pluripotent stem cells [PSCs, including embryonic stem cells (ESCs) and induced pluripotent stem cells (iPSCs), tissue stem cells, adult stem cells (ASCs), or tumor stem cells] in vitro. Organoids reproduce the morphological structure, physiological function, gene specificity, and other characteristics of the source tissue. At present, the word "organoid" refers to a 3D culture described publicly for the first time by Sato et al. (2009). Under certain cytokine-rich matrix culture conditions, single LGR5+ intestinal stem cells (ISCs) can form and maintain an organ-like structure composed of different cells with a crypt-villus structure, which is highly similar to that of freshly isolated small intestinal crypt-villus structure (Sato et al., 2009). Thereafter, organoids were developed and used as a new research model independent of traditional cell lines and heterogeneous animal models.

According to the PubMed literature search by Simian et al., the number of publications that used "organoids" as keywords has increased sharply since 2011, which reveals the vigorous development of the research on organoid models (Simian and Bissell, 2017). Organoids provide a completely different new research model for medical research, including histopathology (Pott et al., 2018), drug development and screening (Fong et al., 2018), and precision medicine (Pauli et al., 2017). However, compared with the traditional cell line model and xenograft animal model used for decades in research and practice, many researchers still know little about organoids, and the model is still in its infancy.

Herein, we will systematically show, summarize, and review the advantages and disadvantages of disease models; integrate the research of organoids in cancer, infectious diseases, genetic diseases, regenerative medicine in recent years; and further discuss the main limitations and breakthroughs. 
TABLE 1 | Advantages and limitations of cell lines and xenografts.

\begin{tabular}{|c|c|c|}
\hline Models & Advantages & Limitations \\
\hline \multirow[t]{4}{*}{ Cell lines } & Low cost and save time & Only represent a subgroup of research objects \\
\hline & Easy to maintain and expand & Loss of the original tissue heterogeneity \\
\hline & High-throughput drug screening & Cannot receive signals, such as those in vivo \\
\hline & Suitable for gene editing & \\
\hline \multirow[t]{3}{*}{ Patient-derived xenograft animal models } & Maintain the three-dimensional structure & More time-consuming and expensive \\
\hline & Interact with the host matrix and immune cells & Animal cells replace the primitive human cells \\
\hline & Better preclinical treatment strategies & Loss of the original tumor heterogeneity \\
\hline
\end{tabular}

These will help more readers understand the application of organoids, improve disease research, and promote organoid development.

\section{Comparison of Organoid Models With Other Models}

Human tissue is a precise and rigorous whole composed of various cells, a specific structure, and its surrounding microenvironment. The cell line model and xenograft animal model are the most commonly used research models, which provide a platform for the development of medicine. However, the complexity of physiological and pathological responses between a single cell line and humans with multiple cells is unparalleled. There is species specificity between the physiological and pathological responses of humans and other animals. However, their limitations cannot meet the needs of all research kinds. Thus, there is an urgent need for a model that conforms to the human physiological and pathological environment as much as possible for scientific research (Table 1).

\section{Cell Lines}

In 1907, Harrison inoculated isolated frog embryo medulla tissue onto frog lymph blocks, thus opening up an experimental method of cultivating cells on glassware. This experimental method is the beginning of tissue culture technology, from which cell lines became inseparable from the development of medicine. Cell lines have remarkable advantages. For example, they are inexpensive, easy to maintain, and expand, and the technology is relatively simple. Cell lines are suitable for high-throughput drug screening, and multiple cell line populations with histological and genetic changes can simulate different clinical situations and drug responses (Iorio et al., 2016; Lee et al., 2018a). Cell lines are also suitable for gene editing (Tang et al., 2016; Liao et al., 2017; Xia et al., 2017). Through superior gene editing, significant progress was made in discovering carcinogenic and molecular targets in vitro. Therefore, cell lines are the most widely used research model in the past few decades, as they play an irreplaceable role in disease development research and drug screening.

However, the cell line model has two main limitations. The cell line consists of a single cell, likely representing a subgroup of research objects (Ben-David et al., 2018). First, cell line survival is affected by pressure that is highly sensitive to culture conditions, and persistent instability can quickly lead to the heterogeneity of the cell line. With time, the cell line finally loses the ability to generalize the heterogeneity of the original tissue. Second, the cell line model has twodimensional (2D) growth, with neither external signals from adjacent cells nor distal external signals from the circulatory system. Therefore, this model cannot reflect vital structures and microenvironments that usually occur under specific physiological or pathological conditions. For example, in tumor development, microenvironmental factors such as blood and lymphatic system (Mazzone and Bergers, 2019), surrounding fibroblasts (Hussain et al., 2020), and mechanical stimulation (Sewell-Loftin et al., 2020) affect the behavior and molecular characteristics of cancer cells and thus change the invasive ability of cancer, resistance to chemotherapy, and growth in vivo. Given these main limitations, traditional cell line disease models often misestimate the disease development and treatment response in vivo, which seriously limits the application of cell line models in experimental research.

\section{Patient-Derived Xenografts}

PDX are the most common tumor models established by transplanting human tumor tissues/cells in animal hosts (usually immunodeficient or humanized mice) (Lai et al., 2017). The first patient-derived tumor xenograft animal model was established in the 1950s (Toolan, 1953). In research using PDX model, the aim was to obtain a group of animals with diseases similar to those of humans and conduct medical experiments to obtain preclinical results (Byrne et al., 2017). PDX can grow in a $3 \mathrm{D}$ microenvironment rich in nutrients and oxygen, can interact and communicate with the host matrix and immune cells, and can maintain the original 3D structure of the tumors and original genomic and phenotypic characteristics. Therefore, they are more suitable for use in predicting drug responses (Gao et al., 2015; Drapkin et al., 2018) and in preclinical host trials (Farago et al., 2019; Savaikar et al., 2020) and for testing the efficacy of new strategies (Stewart et al., 2017). Based on the above advantages, PDX have excellent predictive value and are indispensable for result authentication in essential clinical experiments.

However, the PDX model still has some limitations. PDX models are more time-consuming and expensive than other research models. Moreover, experiments using PDX require ethical approval and consideration of animal welfare and are strictly regulated (Biller-Andorno et al., 2015). With tumor subcultures, mouse stromal cells will replace the primitive human stromal cells and immune cells (Braekeveldt et al., 2016). During the administration of PDX, PDX-specific copy 


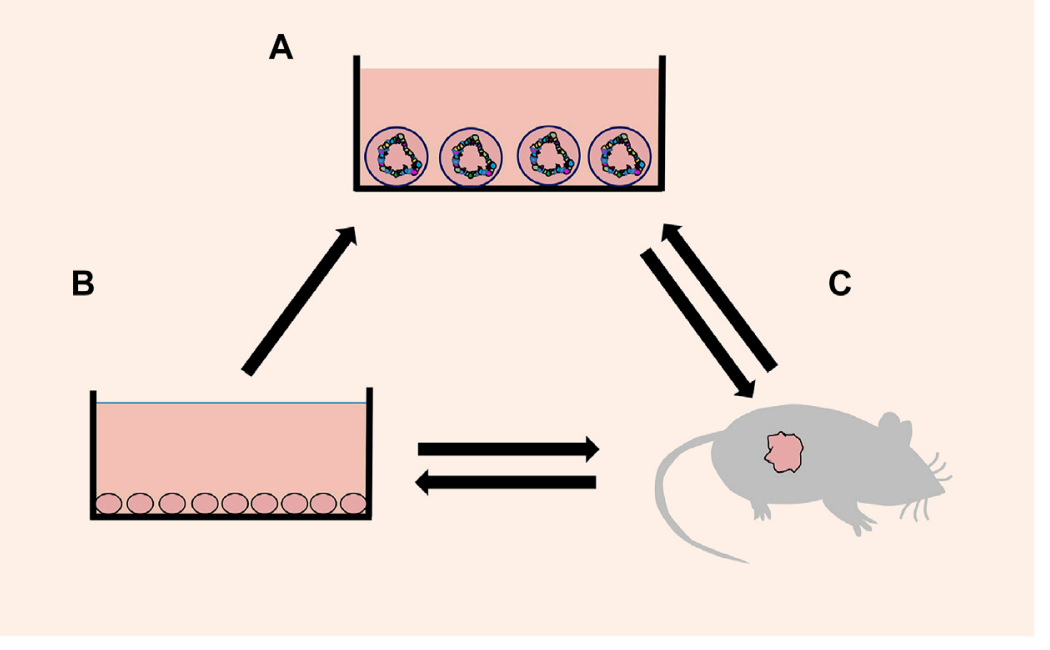

FIGURE 1 | Schematic diagram of mutual transformation. (A) Organoids: a 3D cell culture, which reproduces the cell composition, morphological structure and other characteristics of the source tissue. (B) Cell lines: a 2D cell culture consisting of a single cell. (C) Xenografts: transplantation of human tissue/cells or directly induced animal models.

number alterations gradually disappear and primitive heterogeneity was lost (Ben-David et al., 2017; Ben-David et al., 2019). The genomic map and tumor microenvironment will affect treatment response. In the era of targeted and precision therapy, clinical results are inconsistent with the results of animal experiments, which lower the predictive value of PDX.

\section{Organoids}

Given the limitations of cell lines and PDX, scientists constantly aim to construct a new research model, which has the advantages of both cell lines and PDX. Until 2009, Sato et al. (2009) first described an organoid culture system that allows ISCs to expand in vitro for a long time in a $3 \mathrm{D}$ extracellular matrix (ECM), which opened the prelude to the new era. In the past 10 years, organoids are extensively applied to understand stem cell biology, organogenesis, and human pathology and made considerable breakthroughs in disease mechanism research, drug screening, and precision treatment.

Organoids have significant advantages, as they require relatively less time and money but offer a high success rate. Organoids retain the 3D structure of the original tissues, faithfully summarizing the genetic and phenotypic heterogeneity of the original tissue (Cristobal et al., 2017). Organoids can be a platform in screening drugs with high efficiency and sensitivity, guiding clinical precision treatment and personalized treatment (Pauli et al., 2017). Organoids are also suitable for gene editing. For example, combining the CRISPR-Cas9 system and organoids provides a new opportunity to study tumor gene mutation (Drost et al., 2017). Organoids can be transformed into other models (Jian et al., 2020), cooperate and construct a biological bank (biobank) (Kim et al., 2019; Zhang et al., 2021), to establish a comprehensive and accurate experimental platform. However, organoids still have limitations. Thus, the second half of this review will focus on the current predicament and future development.

As a new research model and development platform, organoids fill the gap between the cell line and PDX (Figure 1), support the existing model system, and extend basic biological research, medical research, and drug discovery to the human environment related to physiology. In the future, the study of organoids has a broad prospect, and an increasing number of scientists will pay attention to organoids and combine them more widely and deeply with various fields of medical research.

In the past 10 years, organoids break through the simple physical contact between cells and form closer biological communication; i.e., organoids break through the dilemma that it is difficult for PDX to replicate physiological processes that exist only in humans. Moreover, we will take cancer, infectious diseases, genetic diseases, and regenerative medicine as examples to show the potential of organoids and attract more scholars to use this technology in the future.

\section{ORGANOIDS AS DISEASE MODELS}

\section{Organoids in Cancer Research}

Cancer is a significant health problem worldwide. Scientists predict that the incidence of all cancer types will increase from 12 million in 2008 to 22 million by 2030 (Berkers et al., 2019). The incidence of and mortality from cancer increase in developing countries, so cancer research has a long way to go (Feng et al., 2019). We have performed much in-depth investigation on the origin, pathology, and genetics of cancer in the past few decades, and we found that the knowledge gained from cell lines and PDX is not entirely consistent with the actual clinical situation. We are increasingly aware that cancer has different heterogeneity and 

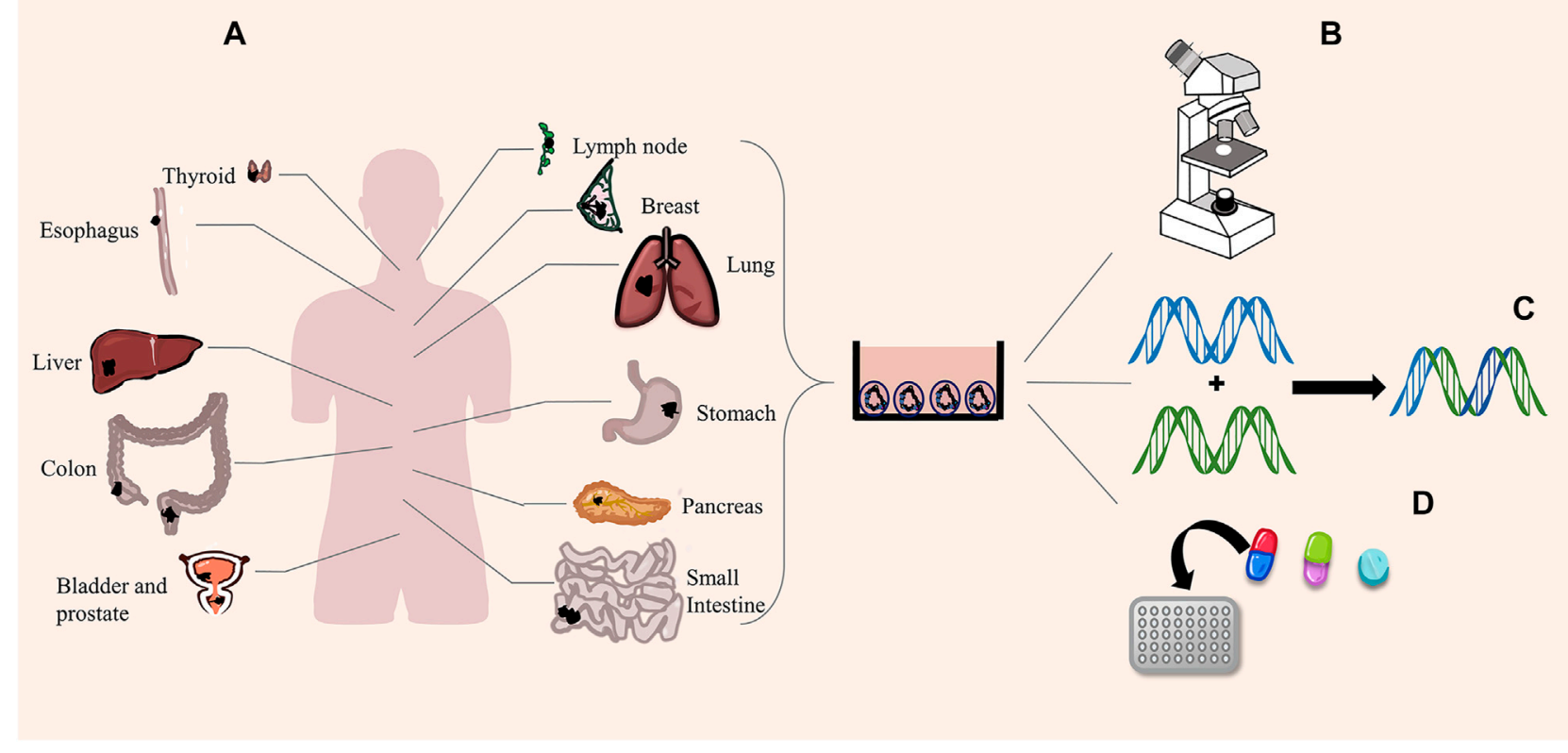

FIGURE 2 | Tumor organoids and functions. (A) Scientists successfully cultured different cancer organoids. (B) Organoids perfectly simulate the pathological expression and tissue structure of tumors. (C) Organoids are suitable for gene editing. (D) High-throughput screening of drugs.

plasticity; thus, how to treat it accurately is very important to the survival and prognosis of patients with cancer. The recently developed 3D culture technology has led to the development of new and more physiological organoids, thus creating new and more targeted therapies. In the more than 10 years since the emergence of organoids, scientists successfully cultivated all kinds of tumor organoids, such as bladder cancer (Lee et al., 2018b), colorectal cancer (van de Wetering et al., 2015), lung cancer (Dijkstra et al., 2020), liver cancer (Nuciforo et al., 2018), prostate cancer (Puca et al., 2018), breast cancer (Han et al., 2020), gastric cancer (Yan et al., 2018), pancreatic cancer (Seino et al., 2018), lymphatic cancer (Tian et al., 2015), esophageal cancer (Li et al., 2018), thyroid cancer (Sondorp et al., 2020), among others (Figure 2). These studies have shown that tumor organoids are highly similar to the original tumors in terms of genetic specificity, epigenetic characteristics, morphology, metabolism, proliferation rate, and metastatic potential. Moreover, organoids build a more suitable platform for exploring new therapeutic targets and high-throughput screening of drugs.

For example, in lung cancer, the global estimates of cancer morbidity and mortality compiled by the International Agency for Research on Cancer in 2018 show that lung cancer is the most common cancer (accounting for $11.6 \%$ of total cases) and the leading cause of cancer death ( $18.4 \%$ of total cancer deaths). There are 2.1 million new cases and 1.8 million deaths annually (Bray et al., 2018). The emergence of organoids brings new impetus to the research of lung cancer.

Lung cancer has various manifestations, and whether organoids can reproduce the unique tissue structure and epigenetics of patients is the first problem to address. In one study, the structure of the organoids of patients with lung cancer ranged from thin-walled cystic structures to dense spherical cell clusters, containing 50\% mutations, and more than $70 \%$ of the cells expressed acetaldehyde dehydrogenase, which maintained the biological characteristics of tumor biopsies (Jung et al., 2019). Once the primary lung cancer tissue is obtained, organoids can be continuously regenerated and replicated in vitro, and the cytological characteristics of the tumor remain stable. The clinical markers remained unchanged during the passage, which lays a foundation for follow-up research. For lung cancer types in which patient samples are lacking, gene editing is combined with organoids to create new possibilities. Some scholars used the CRISPR-Cas9 system to edit multiple genes in lung organoids and showed that the transfected organoids expressed primary cell-specific markers of lung squamous cell carcinoma, such as cytokeratin 5, p63, and epithelial cell adhesion molecule. This kind of gene-edited organoids can be applied in immune checkpoint therapy combined with drug-screening platforms (Hai et al., 2020). Gene editing is a feasible method for rapid mass production of organoids, and this significantly facilitates lung cancer research. However, gene editing can lead to mutations, instability, and uncertainty. Thus, whether the tumor organoids obtained by gene editing are entirely consistent with the source patients is a question worth considering. Drug screening is a strict demonstration process, and the effect of drugs screened through organoids needs to be verified by more experiments. Moreover, this process provides us with an economical and rapid method of studying the critical targets of the tumor.

Drug development and screening is a rigorous and essential process. In the past, PDX have been used as the last barrier before clinical trials. However, the complexity and high cost of 
PDX limit large-scale drug trials. A current comparative study of non-small cell lung cancer showed that the sensitivity of KRAS-mutant organoids to the MEK inhibitor trametinib was consistent with the relative PDX model. By contrast, organoids without KRAS mutations were as resistant as relative PDX (Shi et al., 2020a). This finding suggests the feasibility of replacing PDX with organoids as a drug testing platform, which significantly reduces the cost of large-scale screening. As an in vitro model, organoids still lack many mechanisms that affect drug responses, such as drug metabolism and tissue infiltration; thus, confirming the consistency and effectiveness of the organoids' response to drugs in vivo and in vitro is important. Wang et al. established a 15 patient-derived nonsmall cell lung cancer organoid model with human epidermal growth factor receptor 2 mutation. Drug screening for those organoids shows that pirotinib had a more significant inhibitory effect on organoid proliferation than afatinib in vitro. In the final clinical trial, the results were the same as drug screening of organoids, and pirotinib showed good efficacy (Wang et al., 2019). This study shows that organoids are more feasible in clinical tumor treatment and can help shorten the absolute distance between clinic and laboratory. Considering that lung cancer has various biological and molecular subtypes, genetic heterogeneity is an essential factor that affects the response to drug therapy. We still need to establish biobanks with a large number of data. The era of single-drug treatment for all patients has passed, and the future focuses on the era of personalized and accurate treatment. Organoids have a great application prospect in biobanks. Kim et al. established a biobank derived from 80 lung cancer organoids. The organoid biobank covers more than $95 \%$ of lung cancer types, including adenocarcinoma, squamous cell carcinoma, small cell carcinoma, adenosquamous cell carcinoma, and large cell carcinoma. They screened targeted drugs such as docetaxel, olaparib, erlotinib, and crizotinib, showing that organoid biobanks can predict patient-specific drug responses in vitro as well as proof-of-concept studies of new targeted drugs based on genetic changes (Kim et al., 2019). The development of organoid models is significantly conducive to drug development and screening. In the future, we also need to increase the sample size of organoid biobank. Through multiomics technology to analyze tumor organoids, coupled with large-scale drug screening, data are analyzed by artificial intelligence. Finally, the multi-omics data of tumor organoids are related to drug sensitivity and realize personalized and accurate treatment.

By understanding the biology of tumor organoids and apply them in clinical practice, a preclinical cancer model is needed. We have discussed the main characteristics and application of organoid technology in cancer. Although it is still in the early stage of exploration, the prospect is up and coming. The results of this series of organoid studies on various cancers continue to send us a clear message: Tumor organoids can maintain the phenotype and genetic heterogeneity of the primary tumor. Tumor organoid research can deepen our understanding of the mechanism of tumorigenesis and provide a possible method of treating tumors.
Moreover, organoids can carry out high-throughput drug screening and contribute to the development of precise and personalized treatment.

\section{Organoids in Hereditary Diseases}

Approximately $5.3 \%$ of infants will suffer from genetic diseases when followed up until age 25 years (Verma and Puri, 2015). Many genetic diseases take time to develop in a specific tissue microenvironment, and a traditional single cell line cannot simulate these diseases. In addition, xenograft models do not entirely simulate the characteristics of genetic diseases in humans, such as diseases that affect neurodevelopment and the brain. Thus, further research on cell lines and xenografts in genetic diseases is not needed. Organoids can summarize the organ's structure and function and retain the tissue's original genetic and epigenetic state, which are suitable for gene editing. These aspects are crucial for modeling genetic diseases caused by one (single gene) or multiple (multifactor) abnormalities.

Genetic diseases are mainly caused by mutations of various genes, which make it difficult for cell lines and xenografts to simulate these genetic diseases. Thus, the best choice is to use organoids from the source patient (Table 2). Cystic fibrosis (CF) is an autosomal recessive hereditary disease. The imbalance of chloride channels controlled by transmembrane conductor receptors affects the epithelial cells of many organs such as the lung, pancreas, sweat gland, liver, kidney, and intestine. The corresponding imbalance results in pancreatic insufficiency, gastrointestinal symptoms, and progressive lung diseases. In the past, symptomatic treatments, such as mucolytic agents, anti-inflammatory drugs, and antibiotics, were employed (Villanueva et al., 2017). Because organoids perfectly maintain the genetic specificity of the source tissue, the research on organoid technology to unravel the complex molecular mechanisms and drug screening has increased. Herein, we focused on the breakthrough in CF owing to the combination of organoids and gene-editing technology. The combination of organoids and gene-editing technology brings new hope for the complete cure of CF. In 2013, Schwank et al. used the CRISPR-Cas9 genome-editing system to correct the site of the CF transmembrane conductor receptor (CFTR) through homologous recombination in $\mathrm{CF}$ patient-derived intestinal and colonic organoids, and this provided a theoretical basis for gene correction by homologous recombination in primary ASCs from patients with single-gene hereditary defects (Schwank et al., 2013). Subsequently, gene editing corrected proximal lung organoids and patient-derived adenocarcinoma cell line CFPAC1 (Ruan et al., 2019), intestinal organoids, and airway epithelial cells from patients with CF (Maule et al., 2019), and nasal mucosa of CF mice and patient-derived small intestinal organoids (Dekkers et al., 2013; Vidović et al., 2016). The chloride channel has been effectively repaired and specific function restored, which shows the feasibility of implanting the edited organoids back into the body. In a recent study, Maarten et al. described a biobank of CF intestinal organoids, representing 664 patients, and believed that $20 \%$ of them could theoretically enable efficient repair of nonsense mutations in CFTR through adenine base editors (Geurts et al., 2020). Although gene-edited organoids 
TABLE 2 | Unique advantages of organoids in hereditary disease.

\begin{tabular}{|c|c|c|c|c|}
\hline $\begin{array}{l}\text { Report } \\
\text { year }\end{array}$ & Cellular input & Organoids & Disease & Applications \\
\hline 2013 & $\begin{array}{l}\text { Murine and human } \\
\text { intestinal stem cells }\end{array}$ & Epithelial organoids & Cystic fibrosis & $\begin{array}{l}\text { Disease model; CRISPR-based genome editing; Gene therapy } \\
\text { Schwank et al. (2013) }\end{array}$ \\
\hline 2015 & Human rectal stem cell & Intestinal organoids & Cystic fibrosis & Disease model; Gene therapy Vidović et al. (2016) \\
\hline 2016 & Human iPSC & Optic cup organoids & Leber congenital amaurosis & $\begin{array}{l}\text { Disease model; Pathological mechanism; Drug screening Parfitt } \\
\text { et al. (2016) }\end{array}$ \\
\hline 2017 & Mouse Liver tissues & Liver organoids & Alagille syndrome & $\begin{array}{l}\text { Verify the characteristics of the Jag1Ndr/Ndr mouse model } \\
\text { Andersson et al. (2018) }\end{array}$ \\
\hline 2017 & Human iPSC & Forebrain-type organoids & Miller-Dieker syndrome & $\begin{array}{l}\text { Disease model; Pathological mechanism; Modeling of cell-cell } \\
\text { communication lefremova et al. (2017) }\end{array}$ \\
\hline 2017 & Human iPSC & Cerebral Organoids & Miller-Dieker syndrome & $\begin{array}{l}\text { Disease model; Pathological mechanism; Single-cell RNA } \\
\text { sequencing Bershteyn et al. (2017) }\end{array}$ \\
\hline 2017 & Human iPSC & Hepatic organoids & Alagille syndrome & $\begin{array}{l}\text { Disease model; CRISPR-based genome editing; Gene therapy } \\
\text { Guan et al. (2017) }\end{array}$ \\
\hline 2018 & Human iPSC & Cerebral organoids & Sandhoff disease & Disease model; Pathological mechanism Allende et al. (2018) \\
\hline 2018 & Human iPSC & Retinal organoids & Retinitis pigmentosa & $\begin{array}{l}\text { Disease model; CRISPR-based genome editing; gene therapy } \\
\text { Deng et al. (2018) }\end{array}$ \\
\hline 2018 & Human iPSCs & Retinal organoids & $\begin{array}{l}\text { Leber congenital amaurosis } \\
\text { type } 10\end{array}$ & Drug screening Dulla et al. (2018) \\
\hline 2019 & Human iPSCs & Cerebral organoids & $\begin{array}{l}\text { Juvenile form of neuronal ceroid } \\
\text { lipofuscinosis }\end{array}$ & $\begin{array}{l}\text { Disease model and pathological mechanism Gomez-Giro et al. } \\
\text { (2019) }\end{array}$ \\
\hline 2019 & Human iPSCs & Proximal lung organoids & Cystic fibrosis & $\begin{array}{l}\text { Disease model, CRISPR-based genome editing, and gene } \\
\text { therapy Ruan et al. (2019) }\end{array}$ \\
\hline 2019 & $\begin{array}{l}\text { Human primary rectal } \\
\text { stem cells }\end{array}$ & Intestinal organoids & Cystic fibrosis & $\begin{array}{l}\text { Disease model, CRISPR-based genome editing, and gene } \\
\text { therapy Maule et al. (2019) }\end{array}$ \\
\hline 2020 & Human iPSCs & Cerebral organoids & Schizophrenia & $\begin{array}{l}\text { Disease model and pathological mechanism Benson et al. } \\
\text { (2020) }\end{array}$ \\
\hline 2020 & Human iPSCs & Retinal organoids & X-linked retinitis pigmentosa & $\begin{array}{l}\text { Disease model, pathological mechanism, and CRISPR-based } \\
\text { genome editing Lane et al. (2020) }\end{array}$ \\
\hline 2020 & $\begin{array}{l}\text { Human intestinal stem } \\
\text { cells }\end{array}$ & $\begin{array}{l}\text { Intestinal organoids and } \\
\text { airway organoids }\end{array}$ & Cystic fibrosis & $\begin{array}{l}\text { Organoid biobank, adenine-based editing gene therapy Geurts } \\
\text { et al. (2020) }\end{array}$ \\
\hline
\end{tabular}

iPSCs, induced pluripotent stem cell.

have made some achievements in animal models, their efficiency is very low, and the success rate is not high. More importantly, the safety, long-term stability, and functionality of gene-edited organoids should be tested over time.

With the establishment and application of organoids, this $3 \mathrm{D}$ method has been developed rapidly in basic research and transformation research of genetic diseases. Organoids and gene editing show the potential to completely cure CF, and CF may 1 day be cured by this technique. Organoids create an exciting new opportunity for human genetic diseases in vitro and bring the dawn for the final cure of genetic diseases through gene-editing technology.

\section{Organoids in Infectious Diseases}

Research on human infectious diseases is limited by the lack of normal human physiological and pathophysiological functional models. In the traditional research model, the classical single-cell culture system cannot reproduce complex and dynamic responses or cell-cell interactions. Xenograft animal models may respond similarly to human models, but species-specific differences may lead to an unfaithful display of disease cycles and human responses. The application of organoids allows for the examination of complex physiological or pathological processes in more similar structures under in vivo conditions and paves the way for studying infection and host-source interaction (Figure 3). A model of the interaction among parasites, bacteria, viruses, and other pathogens and their hosts has been established, such as cryptosporidium and small intestine and lung organoids (Heo et al., 2018), Zika virus and brain organoids (Cugola et al., 2016), hepatitis B virus and functional liver organoids (Nie et al., 2018), and Salmonella typhimurium and intestinal organoids (Forbester et al., 2018).

Regarding severe acute respiratory syndrome coronavirus 2 (SARS-CoV-2), as of July 2021, nearly 180 million cumulative cases and more than 4 million deaths were confirmed worldwide. Common symptoms of coronavirus disease 2019 (COVID-19) include fever, cough, and shortness of breath, and the most common cause of death is respiratory failure, combined with metabolic complications in other body systems, including the cardiac, renal, nervous, and gastrointestinal systems (Wiersinga et al., 2020). Patient-derived organoids have various cell types, molecular expression patterns, genetic markers, etc., contained in the corresponding body organs, which can simulate the pathogenic process of human infection, reflect the whole process of infectious diseases intuitively, and provide the possibility for studying the characteristics of pathogens and the interaction between human hosts and pathogens. With the recent SARS-CoV-2 pandemic, determining appropriate therapeutic drugs is the top priority. Han et al. developed human pluripotent stem cells lung organoids (hPSC-LOs) for 


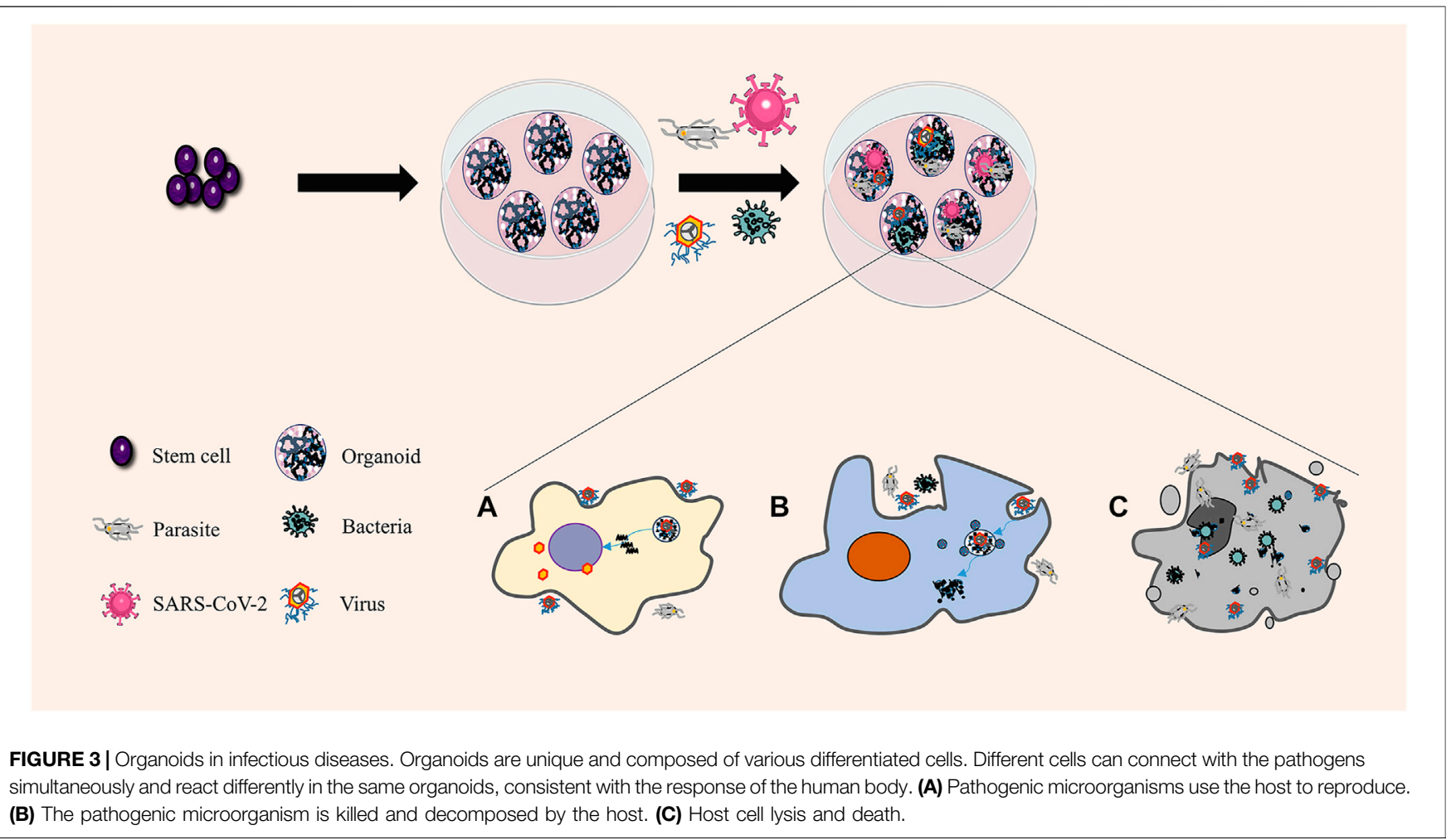

SARS-CoV-2 and SARS-CoV-2 colon organoids (hPSC-COs), and high-throughput screening showed that imatinib, mycophenolic acid, and quinacrine dihydrochloride significantly inhibited SARS-CoV-2 (Han et al., 2021). This indicates the use of SARS-CoV-2-infected hPSC-LOs and hPSC-COs as valuable research models for screening drugs to identify candidate therapeutic agents for COVID-19. In addition, scientists have established models of common complications in patients with SARS-CoV-2 infection, for example, the SARSCoV-2 infection of a human intestinal organoid model (Lamers et al., 2020; Stanifer et al., 2020; Zhou et al., 2020), SARS-CoV-2 infection of a human renal organoid model (Monteil et al., 2020; Xia et al., 2020), SARS-CoV-2 infection of a human brain organoid model (Jacob et al., 2020; Ramani et al., 2020), and SARS-CoV-2 infection of a human liver organoid model (Schultz et al., 2020; Yang et al., 2020; Zhao et al., 2020). These models laid the foundation for the organoid biobanks of SARS-CoV-2 infection, which provide valuable models for drug screening and evaluation of antiviral therapy. With the use of increasingly different SARS-CoV-2 infection organoids, we will know more about the characteristics and disease mechanism of SARS-CoV-2 from different aspects.

In addition to existing drug screening, novel drug development and drug combinations are top priorities of research. SARS-CoV-2 uses angiotensin-converting enzyme 2 (ACE2) and transmembrane serine protease 2 as the main entry point into host cells (Ziegler et al., 2020), and as confirmed in related organoids (Mahalingam et al., 2021), many studies on drug developments have focused on these two targets. Some scientists have designed a humanized decoy antibody (ACE2-Fc fusion protein) that neutralizes SARS-CoV-2 infection, transforming angiotensin II (Ang II) into Ang II-VII and activating natural killer cells (Huang et al., 2021). This antibody may be applied in health care workers or high-risk groups to prevent SARSCoV-2 infection. In the combination drug therapy, anti-androgen drug therapy can reduce the expression of ACE2 and protect hESC-derived lung organoids from SARSCoV-2 infection (Samuel et al., 2020). Combining humanrecombinant soluble ACE2 or human neutralizing antibody with remdesivir effectively inhibits SARS-CoV-2 replication and significantly improves efficacy (Pei et al., 2020; Monteil et al., 2021). Because of the excellent characteristics of organoid models, the drugs and treatment methods developed using SARS-CoV-2 infection organoids are believed to be more reliable and effective, so clinical trials are conducted more quickly.

Organoids are different from cell lines and xenograft animal models and ideally represent all the cellular components of organs of specific species. Theoretically, they are very suitable for investigating infectious diseases, especially those caused by pathogens. Considering the toxicology of drugs, it will be more reasonable to transplant organoids into animal models and then verify the efficacy of related drugs. Organoids bring about a new method of drug screening, treatment, and vaccine of COVID-19, which will help contain the pandemic.

\section{Organoids in Regenerative Medicine}

Regenerative medicine applies biological and engineering theories and methods to restore lost or functionally damaged tissues and organs. Regenerative medicine restores the function of 
TABLE 3 | Organoids used regenerative medicine research.

\begin{tabular}{|c|c|c|c|c|}
\hline $\begin{array}{l}\text { Report } \\
\text { year }\end{array}$ & Cellular input & Organoids & Transplant site & Results \\
\hline 2014 & Mouse small intestinal stem cells & $\begin{array}{l}\text { Small intestinal epithelial } \\
\text { organoids }\end{array}$ & Mouse colon & $\begin{array}{l}\text { Reconstitute self-renewing epithelial and show unique } \\
\text { features of the small intestines Fukuda et al. (2014) }\end{array}$ \\
\hline 2016 & $\begin{array}{l}\text { Human primary bronchial epithelial } \\
\text { cells + peripheral cells }\end{array}$ & Airway organoids & Kidney capsule of NSG mice & $\begin{array}{l}\text { Self-organize and mature toward lung tissue-like } \\
\text { structures; remarkable epithelial plasticity Tan et al. (2017) }\end{array}$ \\
\hline 2017 & $\begin{array}{l}\text { Mouse- and human-induced fetal } \\
\text { intestinal progenitor cells }\end{array}$ & $\begin{array}{l}\text { Spherical and budding } \\
\text { intestinal organoids }\end{array}$ & Injured colonic tissues & $\begin{array}{l}\text { Reconstitute colonic and intestinal epithelia Miura and } \\
\text { Suzuki (2017) }\end{array}$ \\
\hline 2017 & Human primary cholangiocyte & $\begin{array}{l}\text { Extrahepatic } \\
\text { cholangiocyte organoids }\end{array}$ & $\begin{array}{l}\text { Surgical defect in mouse } \\
\text { gallbladder wall }\end{array}$ & $\begin{array}{l}\text { Colonize physiological niche and regenerate part of the } \\
\text { biliary tree Sampaziotis et al. (2017) }\end{array}$ \\
\hline 2017 & $\begin{array}{l}\text { Mouse newborn dermal cells and } \\
\text { adult epidermal cells }\end{array}$ & Skin organoids & $\begin{array}{l}\text { Mouse full-thickness skin } \\
\text { wound }\end{array}$ & $\begin{array}{l}\text { Well-formed reconstituted skin with robust hair growth; } \\
\text { cyclic regeneration Lei et al. (2017) }\end{array}$ \\
\hline 2017 & Human pluripotent stem cells & Intestinal organoids & $\begin{array}{l}\text { Mouse injured intestinal } \\
\text { mucosa }\end{array}$ & $\begin{array}{l}\text { Organoid survival, engraftment, and wound repair } \\
\text { Cruz-Acuña et al. (2017) }\end{array}$ \\
\hline 2018 & $\begin{array}{l}\text { Human and primary murine } \\
\text { hepatocytes }\end{array}$ & Hepatocyte organoids & Mouse damaged mouse liver & $\begin{array}{l}\text { Recapitulate the proliferative damage-response and } \\
\text { demonstrate significant graft expansion Hu et al. (2018) }\end{array}$ \\
\hline 2018 & Human colonic stem cell & Colon organoids & Mouse colon & $\begin{array}{l}\text { Reconstruction of the human colon epithelium and multi- } \\
\text { differentiation capacity Sugimoto et al. (2018) }\end{array}$ \\
\hline 2019 & $\begin{array}{l}\text { Human islet cells and amniotic } \\
\text { epithelial cells }\end{array}$ & Islet organoids & $\begin{array}{l}\text { Kidney capsule of diabetic } \\
\text { mice }\end{array}$ & $\begin{array}{l}\text { Viable and functional islet organoids; diabetes reversal } \\
\text { Lebreton et al. (2019) }\end{array}$ \\
\hline 2019 & Mouse sweat gland epithelial cells & Sweat gland organoids & $\begin{array}{l}\text { Mouse back wound and claw } \\
\text { pad with sweat gland injury }\end{array}$ & $\begin{array}{l}\text { Regeneration of epidermis and sweat glands Diao et al. } \\
\text { (2019) }\end{array}$ \\
\hline 2019 & $\begin{array}{l}\text { Human mesenteric lymph nodes } \\
\text { and primary stromal progenitors }\end{array}$ & $\begin{array}{l}\text { Synthetic lymphoid } \\
\text { organoids }\end{array}$ & $\begin{array}{l}\text { Site of resected mouse lymph } \\
\text { nodes }\end{array}$ & $\begin{array}{l}\text { Restore lymphatic drainage and perfusion and support the } \\
\text { activation of antigen-specific immune responses Lenti } \\
\text { et al. (2019) }\end{array}$ \\
\hline
\end{tabular}

tissues or organs in patients with severe injury or chronic diseases. Tissue regeneration and repair face three main problems, namely, donor shortage (Dwyer et al., 2021), immune rejection (Loupy and Lefaucheur, 2018), and ethical issues (Lieber et al., 2018), promoting the search for alternatives. Organoids can be derived from the patient's PSCs and ASCs. They rapidly reproduce in vitro and retain the $3 \mathrm{D}$ structure, function, heredity, and phenotypic specificity of the original tissues. These advantages are essential for transplantable, immune, and functional tissues or organs in vitro, which undoubtedly brings a new dawn for regenerative medicine (Table 3).

As a valuable tool for the research and treatment of intestinal diseases, intestinal organoids are the most promising direction in organoid regenerative medicine research. In the beginning, small intestinal organoids derived from stem cells were transplanted into the mouse intestinal model, and epithelial crypt-like structures, villi, and Paneth cells were found, which had the characteristics of the primitive intestines (Fordham et al., 2013; Fukuda et al., 2014). That study points to the future opportunities for specific gastrointestinal regeneration in patients, and scientists made various efforts in this direction. Others found that intestinal organoids derived from genetically programmed cells had ISC properties. Organoids transplanted into the damaged colon resembled morphologically and functionally at least 3 months (Miura and Suzuki, 2017). Furthermore, Sugimoto et al. established an orthotopic xenograft system for normal human colonic organoids, enabling the stable reconstruction of human colonic epithelium in vivo for more than 10 months (Sugimoto et al., 2018). Organoid transplantation is a rigorous technique that needs time testing. However, whether the implanted organoids can be thoroughly combined with the primary tissues and maintain long-term functional stability still needs further investigation. All the aforementioned studies have shown the importance of organoids in regenerative medicine. However, the application of organoids in human transplantation still requires a suitable stent, which is necessary to reduce tissue rejection and incompatibility. Scientists designed synthetic hydrogels with a four-armed, maleimide-terminated poly (ethylene glycol) (PEG) macromer starting with the carrier (Cruz-Acuña et al., 2017). Synthetic hydrogels support the growth and expansion of human intestinal organoids in vitro and can be used as injection carriers for transport to the damaged intestinal mucosa to promote the healing of an intestinal injury. Organoid transplantation carriers should have the following characteristics: biocompatibility, nontoxicity to the human body and organoids, suitable viscosity, easy to use, and remain in the tissue defect for a long time. In addition, the structure facilitates the connection between organoids and primary tissues.

Owing to the cultivation of various kinds of patient-derived organoids in vitro, we can skillfully avoid or solve donor shortage, immune rejection, and ethical problems in regenerative medicine. At present, the size and proportion of organoids are still a problem in regenerative medicine. Most organoids are still in micron size and have no vascular system and peripheral immune microenvironment; thus, a large-scale reorganization experiment on organoids is required. Moreover, whether an organoid can be combined with the target tissue and form a standard functional unit is the criterion for successful implantation. However, whether the proportion of all cell kinds in organoids is consistent with that of the target tissue and whether it can be maintained during proliferation and differentiation are questions to consider. In the future, continuous development and improvement of organoids will create conditions for organ 
expansion in vitro, functional transplantation into patients, and reconstruction of tissue defects.

Organoids can be cultured by ESCs (Moris et al., 2020), iPSCs (Xie et al., 2020), ASCs (Huch et al., 2015), or tumor stem cells (Shimokawa et al., 2017) under suitable culture conditions in vitro. The cultivation of different organoids requires corresponding cytokines and culture matrices to form a specific microenvironment. The most commonly used culture conditions of organoids have two parts: 1) hydrogels, which are a 3D scaffold for organoid culture that promote the aggregation of $3 \mathrm{D}$-cultured cells and produce the polarity of cell arrangement, and (Simian and Bissell, 2017) cell growth regulatory components, which simulate the ecological conditions of organs in the body, providing various information to maintain the ability of stem cells to selfrenew, proliferate, and differentiate.

The gold standard for cultivating organoids is to simulate the tissue microenvironment in the body as much as possible. Compared with the dynamic microenvironment in vivo, the aforementioned conventional culture conditions of organoids are insufficient, and many key factors are ignored. Organoids have 3 main limitations. First, Current organoids are relatively simple and do have a vascular system. In vivo, tissues are penetrated and complex vascular networks interact to allow the exchange of oxygen, nutrients, waste, and different biochemical interactions between tissues. By contrast, in vitro, the microenvironment of organoids is still incomplete to a large extent. Second, current organoids do not include two critical components of immune factors and cells. Organoids cannot completely simulate the immune microenvironment of various tissues or diseases and lack the physiological process of mutual communication between the organoids and the surrounding immune environment, so they cannot completely simulate the complete response to the corresponding drugs or other treatments. Third, the culture of organoids is inseparable from the matrix, and the composition, structure, chemical, and physical characteristics of the matrix will affect the composition of organoids. However, no matrix meets the needs of this new in vitro model, which significantly limits the large-scale promotion and use of organoids. In the following section, we will focus on these shortcomings faced by similar organs, show the efforts made by scholars to break through the shackles, and point to future directions of research.

\section{CHALLENGES AND BREAKTHROUGHS}

\section{Organoids Vascularization}

At present, organoids are still of micron size, and a particular gap still exists between their functions and normal tissues. A significant factor is the lack of a vascular system. When organoids grow to a certain extent, the cells in the center cannot get enough nutrition, and excretion of metabolic waste in the cells is difficult, limiting the popularization and application of organoids. Two main methods can be employed to construct vascularized organoids: one is "in vivo vascularization" by transplanting organoids into animal models, and the other is "in vitro vascularization," which is implemented by combining gene editing, mixed cell culture, and microfluidic platform.

In in vivo vascularization, vascularized organoids are constructed by transplanting the organoids into the corresponding animal model to promote the connection between the host animal model and the transplanted organoid model through blood vessels. The kidney is one of the organs closest to human blood vessels. The total amount of plasma filtered by humans every day is as high as $200 \mathrm{~L}$. In humans, wastes are removed through the kidneys to maintain the balance of water, acid-base, and electrolytes in the body. Human-derived kidney organoids can be used as disease model; however, a key question is whether a functional vascular system can be constructed. Van et al. found that renal organoids gradually formed a vascular system by transplanting hPSC-derived renal organoids into the renal capsule of immunodeficient mice, and microscopic examination confirmed a functional vascular network between the subcapsular organoids and host blood vessels (van den Berg et al., 2018) (Figure 4). In a follow-up study, after vascularization in the host, renal organoids showed glucan and albumin size selectivity on the glomerular filtration barrier and proximal tubular dextran reuptake (van den Berg et al., 2020). Organoids with functional blood vessels are closer to the actual condition of human tissues in terms of structure and function, so they can be more suitable for establishing disease models and for clinical applications in regenerative medicine. Similarly, organoids are transplanted into the abdominal cavity and brain of mice to establish blood circulation (Raikwar et al., 2015; Mansour et al., 2018; Soltanian et al., 2019).

In in vivo vascularization, organoids are simple to use and a vascular system can be constructed when combined with an animal model. However, the close relationship between the organoids and xenografts. The internal environment makes the organoids form a vascular system with perfusion ability and form a staggered whole with the surrounding tissue so that organoids are really alive. By contrast, this in vivo vascularization model still cannot eliminate the limitations of traditional xenograft animal models. Even more worrying is that when human organoids are transferred into an animal, the complex vascular system will continue to reconstruct organoids. Thus, whether animals will gradually replace the cells, matrix, and structure of organoids needs more research.

In vitro vascularization means promoting the vascularization of organoids in vitro through the mixed culture of different cells, genetic engineering, or construction of various physical and chemical environments without other animal models (Table 4). For example, in brain organoids, some scientists use genetic engineering to make human cortical organs express EVT2 (the known regulatory gene of angiogenesis) to obtain vascular organoids having the characteristics of the blood-brain barrier (Cakir et al., 2019). Some scientists co-culture human ESCs or human multifunctional cells with human umbilical vein endothelial cells in vitro to produce organoids with a welldeveloped reticular or tubular vascular system (Shi et al., 2020b). The co-culture method depends on the introduction of other external angioblasts, which are simple but difficult to 


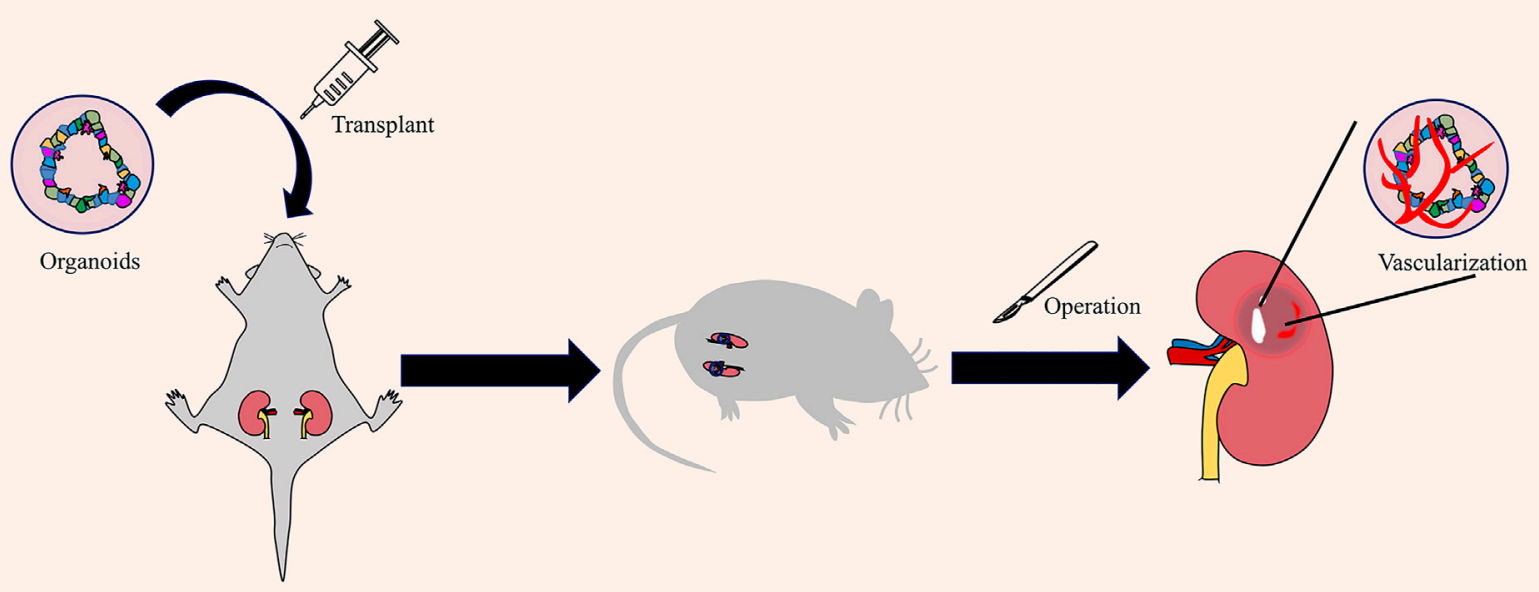

FIGURE 4 | Obtaining vascularized renal organoids by in vivo vascularization. In vivo vascularization is carried out by transplanting organoids into the mouse. The capillaries around the mice will invade the organoid mass and establish vascular circulation.

TABLE 4 | Vascularization of organoids in vitro.

\begin{tabular}{|c|c|c|c|c|}
\hline Category & $\begin{array}{l}\text { Report } \\
\text { year }\end{array}$ & Methods & Organoids & Results \\
\hline \multirow[t]{6}{*}{ Co-culture } & 2018 & Re-embed with endothelial cells & Brain organoids & $\begin{array}{l}\text { Continuity of CD31-positive blood vessels inside the organoids Pham } \\
\text { et al. (2018) }\end{array}$ \\
\hline & 2019 & $\begin{array}{l}\text { Co-culture with endogenous endothelial } \\
\text { cells }\end{array}$ & $\begin{array}{l}\text { Adipose tissue-like } \\
\text { organoids }\end{array}$ & Connected to the recipient circulatory system Muller et al. (2019) \\
\hline & 2019 & $\begin{array}{l}\text { Vascular endothelial growth factor } \\
\text { induction }\end{array}$ & Cerebral organoids & $\begin{array}{l}\text { Vessel-like structures and blood-brain barrier characteristics Ham } \\
\text { et al. (2020) }\end{array}$ \\
\hline & 2020 & $\begin{array}{l}\text { Co-culture with human umbilical vein } \\
\text { endothelial cells }\end{array}$ & Cortical organoids & $\begin{array}{l}\text { A well-developed mesh-like or tube-like vascular system Shi et al. } \\
\text { (2020b) }\end{array}$ \\
\hline & 2021 & Fusion with microvascular fragments & Islet organoids & $\begin{array}{l}\text { Interconnection with surrounding blood vessels and restoration of } \\
\text { normoglycemia Nalbach et al. (2021) }\end{array}$ \\
\hline & 2021 & Fusion with microvascular fragments & Adipocyte organoids & $\begin{array}{l}\text { Fabricate functional, vascularized, adipose-like organoids Strobel } \\
\text { et al. (2021) }\end{array}$ \\
\hline \multirow[t]{3}{*}{$\begin{array}{l}\text { Organoids-on-a- } \\
\text { chip }\end{array}$} & 2019 & Novel microphysiological platform & Retinal organoids & $\begin{array}{l}\text { Vasculature-like perfusion and mature photoreceptor segments } \\
\text { Achberger et al. (2019) }\end{array}$ \\
\hline & 2019 & Culture underflow on millifluidic chips & Kidney organoids & $\begin{array}{l}\text { Vascular network and enhanced cellular polarity and adult gene } \\
\text { expression Homan et al. (2019) }\end{array}$ \\
\hline & 2020 & $\begin{array}{l}\text { A microfluidic platform named } \\
\text { IFlowPlate }\end{array}$ & Colon organoids & $\begin{array}{l}\text { A self-assembled vascular network and innate immune function } \\
\text { Rajasekar et al. (2020) }\end{array}$ \\
\hline \multirow[t]{2}{*}{ Gene editing } & 2019 & $\begin{array}{l}\text { Ectopically express human ETS } \\
\text { variant } 2\end{array}$ & Brain organoids & $\begin{array}{l}\text { Vasculature-like structures and blood-brain barrier characteristics } \\
\text { Cakir et al. (2019) }\end{array}$ \\
\hline & 2021 & Overexpression of PROX1 and ATF5 & Liver organoids & $\begin{array}{l}\text { Vascular morphogenesis and improves native liver functions } \\
\text { Velazquez et al. (2021) }\end{array}$ \\
\hline
\end{tabular}

control. By contrast, the gene-editing method relies on the overexpression of some cytokines and inevitably faces some disadvantages, such as low success rate, gene mutation, technical difficulty, and high cost. Therefore, obtaining organoids with vascular characteristics through gene editing and co-culture is considered sufficient, but these organoids only deliver some oxygen and nutrients and are quite different from actual perfusion vessels. These organoids still need to be transplanted into animals to make the blood vessels genuinely functional.

The traditional in vitro vascularization method is a $2 \mathrm{D}$ culture model that can only cultivate organoids in a pre-added medium under a single culture condition. The complex environment in the body, such as mechanical stress, variable concentrations of nutrient factors, and fluid circulation, is difficult to simulate. Organoids-on-a-chip is the most effective model to simulate 
human functions. Compared with the static control group, the vasculature of renal tubules and glomerulus was enriched, and maturity was enhanced during the development of renal organoids in the presence of blood flow (Homan et al., 2019). In other studies, retina-on-chip provides vascular-like perfusion and, for the first time, can recreate the interaction of mature photoreceptor segments with the retinal pigment epithelium in vitro and could replicate the pathological mechanism and drug reaction in vivo (Rajasekar et al., 2020). The flow of the culture medium is essential for the formation of blood vessels, and organoids-on-a-chip can achieve a higher level of selfassembly, genuinely restoring specific physiological functions, pathological patterns, and drug responses of the prototype organ. Furthermore, a microfluidic platform called IFlowPlate can be used to culture up to 128 independently perfused and vascularized colon organoids in vitro. Tissue extraction is allowed for downstream experimental analysis (Rajasekar et al., 2020). The study is an essential step for the large-scale promotion and use of vascularized organoids. The current microfluidic platform is crude and semi-adjustable but more compliant with the development direction of organoids. To simulate the internal environment as accurately as possible, factors such as shape, concentration of cytokine composition, and flow rate must be considered because they can affect the vascularization of organoids. The microfluidic platform needs to be combined with artificial intelligence. The future microfluidic platform includes but is not limited to the following features: sleek appearance; use of electronic mechanical timing and quantitative injection of new culture medium; adjustable flow rate and direction of liquids; adjustable temperature, humidity, oxygen, and carbon dioxide concentrations; a sensor placed in the tail detects the old culture medium; the injection process is adjusted according to the discharge liquid; and imaging technology monitors blood vessel development in organoids in real time. These features are more compliant with new in vitro, independent, specific, and controllable vascularized organoids pursued by scientists.

\section{Organoids Immune Environment}

The immune system is an important system that performs immune response and immune function. This system comprises immune organs, immunocytes, and immune molecules, identifying and excluding foreign antigenic matter and coordinating with other body systems. Moreover, it maintains the stability of the environment and balances physiological processes within the body and is mainly involved in the development of various diseases. Traditional 2D cell lines can be co-cultured with different immune cells, but this is just a random mix and does not represent the communication between immune cells and other cells and does not characterize the immune microenvironment. If implanted in immunodeficient animals, xenografts limit the interaction between the host immune system and cancer cells. If implanted in immunocompetent animals, xenografts are easily mixed with inherent immune system cells of animals. In the following text, we will introduce the immune research of organoids from three aspects, including immune tissue construction, immune-epithelial interaction, and tumor immune microenvironment.

Since the development of organoids, scientists consider the thymus as the first immune organ. The thymus is a vital lymphoid organ located in the upper part of the anterior mediastinum behind the sternal stalk. Its function is to continuously produce various T-cell populations, which play essential roles in the body's immune function. A study showed that transplantation of thymic organoids into non-thymic nude mice can effectively promote the homing of lymphocyte progenitor cells and support thymic hematopoiesis and immune response (Fan et al., 2015). Further, a recent study showed that combining epithelial-mesenchymal mixed cells with thymic interstitial cells and natural thymic acellular ECM can produce T-cells in humanized immunodeficient mice (Campinoti et al., 2020). These findings lay the foundation for cellular and molecular communications between ECM and thymocytes and provide a practical prospect for the construction of thymic organoids and thymus regeneration in vitro. These provide an opportunity to study tissue growth, development, and treatment of congenital and acquired immune diseases.

The interaction between epithelial cells and immune cells plays an essential role in the physiological balance in mammals. Integrating the interaction network of organoids, immune cells, and related cells is very important for tissue growth and development, establishment of related disease models, drug evaluation, pharmacological testing, and application in regenerative medicine.

In this section, we will discuss the interaction between intestinal epithelial organoids and the surrounding immune environment. In the physiological environment of the small intestine, to maintain the dynamic balance of tissues, the intestinal epithelium regenerates continuously from ISCs to eventually differentiate into intestinal epithelial cells, Paneth cells, tuft cells, etc. Through the experiment using co-culture of organoids with immune cells and related cytokines, different levels of interactions were found between intestinal epithelial organoids and the surrounding immune environment in vitro (Figure 5). Different immune cells and their cytokines play diverse positive and negative roles in this dynamic tissue balance. The intricate interactions between them are the primary conditions necessary for preventing and curbing pathogenic infections and preventing excessive immunoreactive and subsequent tissue damage repair processes (Thaiss et al., 2016). Moreover, many studies are still using co-cultures of single immune cells and organoids, which are far from the complex immune microenvironment of the human body.

Immune cells are essential components of the tumor microenvironment and control cancer progression and drug response (Greten and Grivennikov, 2019). The emergence of tumor immunotherapy also revolutionized cancer treatment and inspired extensive research on tumor immunology and on using this "natural weapon" to gain therapeutic benefits. The problem of applying organoid technology to establish a model of the interaction between tumor and immune cells needs to be solved first. At present, two primary sources of autologous 


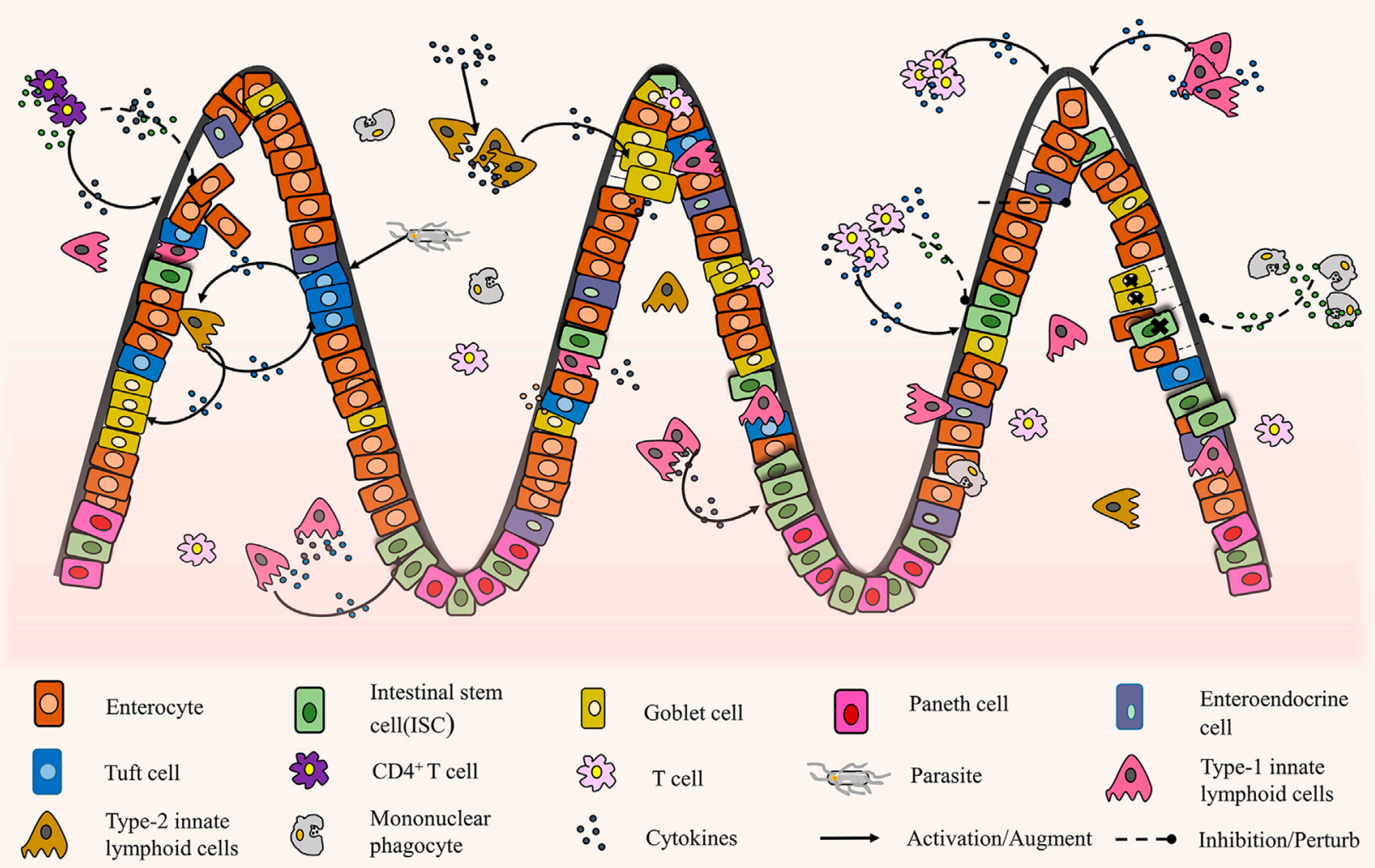

FIGURE 5 | The interaction between intestinal organoids and immune cells (Schreurs et al., 2019; Howitt et al., 2016; von Moltke et al., 2016; Gerbe et al., 2016; Nozaki et al., 2016; Waddell et al., 2019; Lindemans et al., 2015; Biton et al., 2018; Takashima et al., 2019; Jung et al., 2018; Jowett et al., 2021; Ihara et al., 2018).

immune cells introduced into the organoids are available. The first source is the mixed tumor/lymphocyte organoids produced by introducing lymph node components or peripheral blood lymphocytes into the tumor organoids, such as pancreatic ductal adenocarcinoma (Holokai et al., 2020), melanoma (Votanopoulos et al., 2020), and colon tumor (Courau et al., 2019). Those methods model the tumor immune circulation, but most of them used epithelial-only organoids co-cultured with lymphocytes. The immune microenvironment of different tumors varies; even the same tumors have different immune environments. Therefore, a simple mixture of tumor organoids and immune cells cannot obtain the immune microenvironment and cannot be used in the experimental immunotherapy model. The second method is to construct the organoids with an immune environment. Scientists placed the tumor tissue in the air-liquid interface (Neal et al., 2018) or 3D microfluidic culture system (Jenkins et al., 2018), and the results showed that tumor spheres retain the original autologous matrix, related immune checkpoint deletion, tumor-infiltrating lymphoids, and myeloid subsets. This method retains the complex histological structures with tumor parenchyma and stroma, including functional tumor-specific tumor-infiltrating lymphocytes, which can effectively predict tumor development, and the effect of PD-1 or PD-L1 inhibition could be assessed (Neal et al., 2018). However, this method still has limitations, existing culture conditions cannot meet the needs of tumor cells, stromal cells, and immune cells simultaneously, and the unique tumor immune microenvironment will be gradually lost in the culture process. In the future, the development of tumor immune organoids will aid in the immune-oncology study of patient-derived tumor organoids in a tumor-preserving microenvironment. Tumor organoids with an immune microenvironment can aid in the analysis of the pathology between tumor and immune cells, reproduce cancer-related inflammation and canceration, screen and optimize cellular immunotherapy in vitro, and shorten the absolute distance between the laboratory and clinic.

In addition, tumor organoids with immune-vascular interaction have made a breakthrough (Cui et al., 2018). This organoid model can be used to culture tumor cells, endothelial cells, and immune cells from patients in a controllable microenvironment, which is applied to the phenotypic identification of various tumors and allows high-throughput drug screening and real personalized drug screening possible and advances precision medicine a step forward.

\section{Organoids Culture Medium}

ECM is a complex hierarchical network composed of proteins, which affect a series of cell processes, such as adhesion, proliferation, and differentiation. The construction of biomaterials that mimic natural ECM characteristics is significant for studying cell physiology (Zhu et al., 2019). Similarly, in the construction of organoids in vitro, the 
TABLE 5 | Organoids and hydrogels.

Category

Materials

Decellularized matrix

Natura

hydrogel

Organoids

Airway organoids, liver, organoidsetc.
Features

Native microstructure and extracellular matrix (growth factor, protein, etc.)
Nanocellulose fibers

Collagen IV (substrate) +

Collagen I (overlay)

Alginate

Bioactive glass + integrated alginate

Bone forming peptide- $1+$ silica nanoparticles + RGD + alginate

Collagen

Fibrin

Plasma

Synthetic

hydrogel

QGel CN99

Polyisocyanide + RGD

(Arg-Gly-Asp)

Poly (ethylene glycol) (PEG)

+ RGD

PEG + integrin and matrix binder peptides

$P E G$ + RGD + protease-

degradablepeptide

Allyl sulfide

Amikacin

Poly ( $\varepsilon$-caprolactone) + cancerassociated fibroblasts

(CAF) ECM

Gelatin + chondroitin sulfate + Retinal organoids

hyaluronic acid $(\mathrm{HA})$

Gelatin + phenol

Matrigel + collagen I

$P E G+$ fibrin

Hyaluronan $(\mathrm{HA})+$ gelatin

$+\mathrm{CAF}$
Intestinal organoids

Intestinal organoids

Intestinal organoids

HDF cells and KB3-1 cell spheroids

Osteo-differentiation of human mesenchymal stem cells

Thymic organoids and

intestinal organoids

Epithelial organoids

Breast cancer organoids

Colonic organoids

Breast organoids

Liver organoids and intestinal organoids

Intestinal organoids

Intestinal organoids

Intestinal organoids

Pancreatic organoids

Breast cancer organoids

Colorectal cancer organoids

Blood vessel organoids

Lung adenocarcinoma organoids

Colorectal cancer organoids
Well defined, low cost, and appropriate stiffness

Inter-lot stability, accessibility to the apical side, and scalability

Low-cost and controllable physical and biochemical properties

Porous and hardness increase, optima swelling and porosity, and

biocompatibility

Uniform, additional mechanical integrity, suitable elastic modulus, and superhydrophilic property

Biocompatible, biodegradable, easily detectable, and high porosity

Enzymatic gelation and mimic signaling function

A reservoir for nutrients, growth factors, cytokines, and signaling molecules, and low cost

Fully defined hydrogel and freeze-dried preservation

Biocompatibility, soft, stability, and thermal reversibility

Controllable hardness and slow degradation

A rigorously defined microenvironment and suitable storage moduli and swelling

A regular mesh structure with fully swollen and symmetric blocks With photocleavable bonds that temporally regulate the material's bulk modulus

Tunable physiochemical properties

Slow degradation kinetics, open, and well-connected porous architecture

Stable and spongy with a homogenous compressive strength

Controllable hardness and smaller pore sizes with higher storage moduli Similar to natural ECM and stability

Controllable mechanical properties, stability, and biocompatibility

Fully defined hydrogel and tunable biochemical and mechanical properties
Results

A viable approach for the generation of a whole functional organ Du et al. (2016), Tan et al. (2017), Vyas et al. (2018), Giobbe et al. (2019), Mollica et al. (2019), Rezaei Topraggaleh et al. (2019), Bi et al. (2020a), Bi et al. (2020b), Meran et al. (2020), Willemse et al. (2021)

Sustainable and promising microenvironment for organoid growth and budding Curvello et al. (2020), Curvello and Garnier (2021)

Expanding IECs with higher LGR5+ mRNA levels Tong et al. (2018)

Supports human organoid growth in vitro and leads to epithelial differentiation Capeling et al. (2019)

Support the regeneration of bone, intravascularization, and neotissue formation Bargavi et al. (2020)

Enhance hMSC survivability, expansion, and osteogenesis and useful for tissue regeneration and 3D bio-printing Luo et al. (2018)

Supports organoid growth, differentiation, structuralization, and a carrier in vivo Sachs et al. (2017), Bortolomai et al. (2019)

Supports the long-term expansion of all tested murine and human epithelial organoids

Broguiere et al. (2018)

Supporting organoid growth and expansion and high-throughput drug screening and predicting clinically therapies Calar et al. (2020) Supports efficient establishment, expansion, and biobanking of primary human colonic organoids Bergenheim et al. (2020)

Supports (cystic) organoid formation and maintains capacity to branch Zhang et al. (2020) Optimized the efficiency of organoid derivation expansion and formation Gjorevski and Lutolf (2017), Sorrentino et al. (2020)

Long-term growth of human organoids and broadly use for other epithelial organoid culture Hernandez-Gordillo et al. (2020)

Robustly supports $\mathrm{HIO}$ maintenance and an ideal injection vehicle Cruz-Acuña et al. (2017) Provide more uniform and consistent organoid structures and particularly useful in drug screening Hushka et al. (2020)

Significant enhancement of islet phenotype and self-organization into 3D spheroids Candiello

et al. (2018)

Better mimic biochemical and biomechanical properties and capture drug response Nayak et al. (2019)

Favored retinal cell types differentiation and weak immunogenicity Singh et al. (2018)

Support colorectal cancer organoid survival and drug sensitivity $\mathrm{Ng}$ et al. (2019)

Generating blood vessel organoids and a model of diabetic vasculopathy Wimmer et al. (2019) Tumor responses reproduce and more accurately model solid tumors Del Bufalo et al. (2016)

Retained proliferative capacity and preserved molecular characteristics and CRC-CAF Luo et al. (2021)

IECs, intestinal epithelial cells; HDF, human dermal fibroblasts; hMSCs, human mesenchymal stem cells; ECM, extracellular matrix. 
selection and construction of culture medium are also critical. The construction and selection standards of all kinds of in vitro model culture matrices are focused on whether the model can better simulate human physiological and functional environment on a multi-scale from molecule to cell, tissue, organ, and even the whole organism. A hydrogel is a multiphase matrix composed of hydrophilic polymers with high water content, which has a highly porous structure similar to the natural ECM. Hydrogels are recognized as the first choice for simulating biological ECM to construct organoids in vitro because of their high biocompatibility, extraordinary permeability, appropriate elasticity, and hardness (Liu et al., 2019). According to their composition, hydrogels can be roughly divided into natural, synthetic, and hybrid hydrogels (Table 5).

\section{Natural Hydrogels}

The emergence of tissue decellularization technology, coupled with the easy acquisition of animal tissue-specific ECM, makes it possible to use animal-specific natural hydrogels to culture human organoids. Matrigel, the most widely used commercial matrix, is a soluble basement membrane extracted from Engelbreth-Holm-Swarm mouse sarcoma and is rich in ECM proteins, such as laminin (main component), type IV collagen, and various growth factors. However, the composition of mouse sarcoma is unknown, and simulating actual conditions of healthy tissues in the microenvironment of tumor cells is difficult. Therefore, considering the unique ECM of different tissues, different organoids should be matched with the corresponding decellularized matrix. Renal organoids are constructed on decellularized renal matrix scaffold, and the preexisting vascular and filtration systems of the matrix provide a natural conduit, promoting cell self-assembly and regaining of biochemical function (Du et al., 2016). Testicular organoids with spermatogenesis were constructed using a male goat testicular acellular matrix (Rezaei Topraggaleh et al., 2019). Thymic acellular matrix improved T-cell output microenvironment and construction of functional thymic organoids (Hun et al., 2017). ECM hydrogels from decellularized tissues can provide an environment that can guide cell growth and induce corresponding physiological functions. In addition, they have the proteomic characteristics of the source tissues and specific enrichment of significant ECM proteins related to organogenesis, which play crucial roles in regulating organoids. However, the decellularized matrix still has some limitations. There is a potential loss of soluble growth factors and cytokines in different acellular methods; even if the acellular technology is improved, we cannot eliminate such a loss. Animal-derived acellular matrix is at risk of species difference, immunogen, and pathogen transmission. The composition of ECM in different batches maybe is specific, which leads to the difficulty of performing accurate quantitative and qualitative analyses of the cultured matrix, so the experimental results are accidental. These persistent uncontrollable and potential nonphysiological physical environments seriously limit the use of acellular matrix and restrict the clinical and transformational applications of organoids in vitro.
Natural hydrogels have good biocompatibility, and scientists are pleased to find other suitable substitutes. For example, cellulose hydrogel is a kind of plant-based, sustainable, and low-cost soft material. Its mechanical properties are similar to those based on the animal matrix and are easy to be use. Cellulose hydrogel can induce the formation and growth of small intestinal organoids (Curvello et al., 2020). However, these natural hydrogels have relatively poor mechanical properties and insufficient stability, hindering the long-term cell culture in model systems. Hence, nanocellulose hydrogels cross-linked with divalent cations with ideal biochemical and physical properties (Curvello and Garnier, 2021) and alginate with enhanced properties of bioglass (Bargavi et al., 2020) or protein (Luo et al., 2018) are invented. Those new hydrogels have the potential to reduce the cost of biomedical research. Natural hydrogels are biocompatible and have mild physical and chemical properties. Furthermore, they provide biomimetic scaffolds that are rich in cell adhesion sites and wrap cells in situ, and they are easy to use. In the future, natural hydrogels will assist in the transformation and clinical application of organoids.

\section{Synthetic Hydrogels}

The dependence of some poorly defined natural sources of ECM severely limits the application and promotion of organoids on the large scale, prompting scientists to turn to chemical synthesis for help. The complete definition of the ingredients is a prerequisite for the large-scale use of hydrogels, which is critical to the stability and repeatability of the experiment. Synthetic hydrogels used in organoids include QGel CN99 (Bergenheim et al., 2020), polyisocyanide (Zhang et al., 2020), PEG (Cruz-Acuña et al., 2017; Gjorevski and Lutolf, 2017; Hernandez-Gordillo et al., 2020; Sorrentino et al., 2020), allyl sulfide (Hushka et al., 2020), and amikacin (Candiello et al., 2018). Fully defined synthetic hydrogels can be adjusted to have the desired physical properties (stiffness, porosity, elasticity, and absorption) by simply modulating the monomer mole ratio, synthetic microenvironment, or exposure duration (Candiello et al., 2018; Hushka et al., 2020; Sorrentino et al., 2020). Even after hydrogel synthesis, the physical and chemical properties are still controllable. Those properties are critical for biological activities such as expansion, contraction, migration, and differentiation of organoids. For example, solving the mechanical dependence on crypt structures is necessary for the construction of homogenous and reproducible intestinal organoids for clinical applications (Hushka et al., 2020) and elimination of the negative effect of abnormal liver mechanics on the proliferation of liver progenitor cells in organoids (Sorrentino et al., 2020). Avoidance of the adverse effects of hydrogels on organoids is an important part of the standardization of organoids in the future.

The outstanding advantage of synthetic hydrogels is that they reinforceable by adding various proteins. PEG is widely used in drug carriers and tissue engineering because of its unique physical and chemical properties and biocompatibility. RGD is a motif in many ECM proteins, including collagen and fibronectin, which can effectively promote cell adhesion to biomaterials. The combination of PEG and RGD can effectively promote the adhesion of cells to the gel and promote the formation and 
proliferation of organoids (Gjorevski and Lutolf, 2017) and, when combined with integrin and matrix binder peptides, strengthen epithelial cell proliferation and organoid formation (HernandezGordillo et al., 2020). Furthermore, they can be combined with PEG, RGD, and protease-degradable peptide GPQ-W, which is more beneficial to matrix remodeling, cell migration, and growth (Cruz-Acuña et al., 2017). The quantitative and qualitative chemically synthesized matrix has the characteristics of adjustable key properties. Small molecules and soluble factors (such as growth factors) can be connected to hydrogels in a controllable and anisotropic manner through covalent interactions; thus, synthetic hydrogels are becoming more popular. The ECM in organisms has complex structure and composition, and even a small piece of tissue may have different structures and components. A single synthetic hydrogel added only with some factors still cannot meet the needs; hence, more research is desired to explore different structures and components to meet the needs of all kinds of organoids.

\section{Hybrid Hydrogels}

Given the complex environment in the human body, the use of a single type of hydrogel cannot meet all the requirements of constructing organoid models in vitro. Therefore, the hybrid hydrogel with better properties can be prepared by physical blending and chemical modification. The mixed synthetic matrix of natural hydrogels is biocompatible and avoids the disadvantages of some components. As a matrix for human intestinal epithelial cells, collagen I is more accessible to obtain (through various tissues or commercial sources). The ratio of collagen I to Matrigel (1:1) reduced the usage rate of Matrigel, cost, and time, in a sense, on the premise of ensuring the development of organoids (Wimmer et al., 2019). Alternatively, gelatin was used to prevent immunogenicity (Singh et al., 2018) or adjust mechanical strength and gelling rate (Ng et al., 2019; Luo et al., 2021). Natural-synthetic hydrogels may be the best choice, as they combined the advantages of natural and synthetic hydrogels. PEG-fibrin hydrogel forms tumor-stromal interactions and induces more invasive tumor organoids, with more advantages over other 3D systems (Del Bufalo et al., 2016). Fibrin hydrogels have good operation performance and biocompatibility, and changing the total concentration of fibrinogen can control the mechanical properties of these hydrogels. However, fibrin hydrogels are easily degraded by fibrinolytic enzymes and other enzymes, resulting in the uncontrollable and unpredictable loss of mechanical rigidity, low stability, and opacity. Therefore, the addition of PEG increases the stability and transparency of hydrogels. Similarly, poly ( $\varepsilon$-caprolactone) provides an open, well-connected porous structure; decellularizing cancerassociated fibroblasts faithfully reflect the characteristics of ECM and promotes cell attachment and vitality (Nayak et al., 2019). They provide unique environmental and mechanical properties for primary cancer cells, thus improving the survival rate of organoids.

A series of processes such as adhesion, growth, proliferation, and differentiation were performed in the
ECM. Natural, synthetic, and hybrid hydrogels have advantages and disadvantages, but they cannot fully simulate the tissue microenvironment in vivo, and cultural conditions are not entirely controllable. The above research also presents the best method of developing an ideal matrix in the future, including the following aspects: 1) composite hydrogels with various substances, such as bone-forming peptide-1, synergistically enhance the survivability, expansion, and osteogenesis of human mesenchymal stem cells (Sorrentino et al., 2020). Laminin-111 is a key parameter required for robust organoid formation and expansion (Broguiere et al., 2018). Additives enhance the contact between the matrix and organoids and enhance some properties of the hydrogel, which are more conducive to the formation and development of organoids. 2) The hydrogel has a structure similar to that of the environment in vivo, such as the decellularized matrix of homologous tissue (Giobbe et al., 2019; Mollica et al., 2019; Bi et al., 2020a; Bi et al., 2020b; Meran et al., 2020; Willemse et al., 2021), a culture hydrogel of intestinal organs composed of a collagen V-coated porous substrate, and a collagen I gel overlay (Tong et al., 2018); 3D collagen type I scaffolds mimicking the double cortical layer ultrastructure of the thymus (Bortolomai et al., 2019). Different tissues have different structures. The reconstruction of these structures is necessary to restore the structure and function of organoids in vivo, and it will also be the focus of regenerative medicine research in the future. 3) The combination of hydrogel and microfluidic platform forms organoids-on-a-chip, recapitulating the biochemical, mechanical, structural, and functional features of the human cellular microenvironment in vivo. The ECM in vivo is not a continuous layer but a dynamically balanced environment. Just as the ECM will be affected by body fluids, immune products, pressure, $\mathrm{pH}$, oxygen content, and other factors, despite great technical difficulties, the microfluidic platform is also simulated on the hydrogel as much as possible.

\section{CONCLUSION}

Organoids, cell lines, and xenografts have advantages and disadvantages. In experimental research, the most appropriate research model should be chosen according to the purpose, needs, and conditions. This review summarized recent research and advantages of current organoids in tumors, hereditary diseases, infectious diseases, and regenerative medicine, showing the infinite possibility of organoids as a new disease model. In addition, organoids have achieved success in tissue development (Huch and Koo, 2015), drug toxicology (Astashkina and Grainger, 2014), and neuropsychiatric diseases (Mariani et al., 2015). However, the shortcomings of organoids in vascularization, immune microenvironment and hydrogel still exist. Here we summarize and point out the development direction, just to provide reference for more researchers. In the future, organoids are expected to be continuously used in all fields of medical research, combined 
with various scientific and technological means, to constantly develop organoids' potential. Although organoids have various limitations, with the application and improvement of organoids, the gap between its clinical applications will continue to reduce. As a result, it will be increasingly and directly used in the clinical treatment of patients, which has a broad and bright prospect.

\section{REFERENCES}

Achberger, K., Probst, C., Haderspeck, J., Bolz, S., Rogal, J., Chuchuy, J., et al. (2019). Merging Organoid and Organ-On-A-Chip Technology to Generate Complex Multi-Layer Tissue Models in a Human Retina-On-A-Chip Platform. Elife 8. doi:10.7554/eLife.46188

Allende, M. L., Cook, E. K., Larman, B. C., Nugent, A., Brady, J. M., Golebiowski, D., et al. (2018). Cerebral Organoids Derived from Sandhoff Disease-Induced Pluripotent Stem Cells Exhibit Impaired Neurodifferentiation. J. Lipid Res. 59 (3), 550-563. doi:10.1194/jlr.M081323

Andersson, E. R., Chivukula, I. V., Hankeova, S., Sjöqvist, M., Tsoi, Y. L., Ramsköld, D., et al. (2018). Mouse Model of Alagille Syndrome and Mechanisms of Jagged1 Missense Mutations. Gastroenterology 154 (4), 1080-1095. doi:10.1053/j.gastro.2017.11.002

Astashkina, A., and Grainger, D. W. (2014). Critical Analysis of 3-D Organoid In Vitro Cell Culture Models for High-Throughput Drug Candidate Toxicity Assessments. Adv. Drug Deliv. Rev. 69-70, 1-18. doi:10.1016/ j.addr.2014.02.008

Bargavi, P., Ramya, R., Chitra, S., Vijayakumari, S., Riju Chandran, R., Durgalakshmi, D., et al. (2020). Bioactive, Degradable and Multi-Functional Three-Dimensional Membranous Scaffolds of Bioglass and Alginate Composites for Tissue Regenerative Applications. Biomater. Sci. 8 (14), 4003-4025. doi:10.1039/d0bm00714e

Ben-David, U., Beroukhim, R., and Golub, T. R. (2019). Genomic Evolution of Cancer Models: Perils and Opportunities. Nat. Rev. Cancer 19 (2), 97-109. doi:10.1038/s41568-018-0095-3

Ben-David, U., Ha, G., Tseng, Y.-Y., Greenwald, N. F., Oh, C., Shih, J., et al. (2017). Patient-derived Xenografts Undergo Mouse-specific Tumor Evolution. Nat. Genet. 49 (11), 1567-1575. doi:10.1038/ng.3967

Ben-David, U., Siranosian, B., Ha, G., Tang, H., Oren, Y., Hinohara, K., et al. (2018). Genetic and Transcriptional Evolution Alters Cancer Cell Line Drug Response. Nature 560 (7718), 325-330. doi:10.1038/s41586-018-0409-3

Benson, C. A., Powell, H. R., Liput, M., Dinham, S., Freedman, D. A., Ignatowski, T. A., et al. (2020). Immune Factor, TNFa, Disrupts Human Brain Organoid Development Similar to Schizophrenia-Schizophrenia Increases Developmental Vulnerability to TNFa. Front. Cell. Neurosci. 14, 233. doi:10.3389/fncel.2020.00233

Bergenheim, F., Fregni, G., Buchanan, C. F., Riis, L. B., Heulot, M., Touati, J., et al. (2020). A Fully Defined 3D Matrix for Ex Vivo Expansion of Human Colonic Organoids from Biopsy Tissue. Biomaterials 262, 120248. doi:10.1016/ j.biomaterials.2020.120248

Berkers, G., van Mourik, P., Vonk, A. M., Kruisselbrink, E., Dekkers, J. F., de Winter-de Groot, K. M., et al. (2019). Rectal Organoids Enable Personalized Treatment of Cystic Fibrosis. Cell Rep. 26 (7), 1701-1708. doi:10.1016/ j.celrep.2019.01.068

Bershteyn, M., Nowakowski, T. J., Pollen, A. A., Di Lullo, E., Nene, A., WynshawBoris, A., et al. (2017). Human iPSC-Derived Cerebral Organoids Model Cellular Features of Lissencephaly and Reveal Prolonged Mitosis of Outer Radial Glia. Cell Stem Cell 20 (4), 435-449. doi:10.1016/j.stem.2016.12.007

Bi, H., Karanth, S. S., Ye, K., Stein, R., and Jin, S. (2020). Decellularized Tissue Matrix Enhances Self-Assembly of Islet Organoids from Pluripotent Stem Cell Differentiation. ACS Biomater. Sci. Eng. 6 (7), 4155-4165. doi:10.1021/ acsbiomaterials.0c00088

Bi, H., Ye, K., and Jin, S. (2020). Proteomic Analysis of Decellularized Pancreatic Matrix Identifies Collagen V as a Critical Regulator for Islet Organogenesis from Human Pluripotent Stem Cells. Biomaterials 233, 119673. doi:10.1016/ j.biomaterials.2019.119673

\section{AUTHOR CONTRIBUTIONS}

YH, ZH, QY, and BJ wrote the manuscript; ZT, YC, MH, WH and HL made the figures and edited the manuscript; QY and BJ conceived of and supervised the work. All authors have read and agreed to the published version of the manuscript.

Biller-Andorno, N., Grimm, H., and Walker, R. L. (2015). Professionalism and Ethics in Animal Research. Nat. Biotechnol. 33 (10), 1027-1028. doi:10.1038/ nbt.3363

Biton, M., Haber, A. L., Rogel, N., Burgin, G., Beyaz, S., Schnell, A., et al. (2018). T Helper Cell Cytokines Modulate Intestinal Stem Cell Renewal and Differentiation. Cell 175 (5), 1307-1320. doi:10.1016/j.cell.2018.10.008

Bortolomai, I., Sandri, M., Draghici, E., Fontana, E., Campodoni, E., Marcovecchio, G. E., et al. (2019). Gene Modification and Three-Dimensional Scaffolds as Novel Tools to Allow the Use of Postnatal Thymic Epithelial Cells for Thymus Regeneration Approaches. STEM CELLS Translational Med. 8 (10), 1107-1122. doi:10.1002/sctm.18-0218

Braekeveldt, N., Wigerup, C., Tadeo, I., Beckman, S., Sandén, C., Jönsson, J., et al. (2016). Neuroblastoma Patient-Derived Orthotopic Xenografts Reflect the Microenvironmental Hallmarks of Aggressive Patient Tumours. Cancer Lett. 375 (2), 384-389. doi:10.1016/j.canlet.2016.02.046

Bray, F., Ferlay, J., Soerjomataram, I., Siegel, R. L., Torre, L. A., and Jemal, A. (2018). Global Cancer Statistics 2018: GLOBOCAN Estimates of Incidence and Mortality Worldwide for 36 Cancers in 185 Countries. CA: A Cancer J. Clinicians 68 (6), 394-424. doi:10.3322/caac.21492

Broguiere, N., Isenmann, L., Hirt, C., Ringel, T., Placzek, S., Cavalli, E., et al. (2018). Growth of Epithelial Organoids in a Defined Hydrogel. Adv. Mater. 30 (43), 1801621. doi:10.1002/adma.201801621

Byrne, A. T., Alférez, D. G., Amant, F., Annibali, D., Arribas, J., Biankin, A. V., et al. (2017). Interrogating Open Issues in Cancer Precision Medicine with PatientDerived Xenografts. Nat. Rev. Cancer 17 (4), 254-268. doi:10.1038/ nrc.2016.140

Cakir, B., Xiang, Y., Tanaka, Y., Kural, M. H., Parent, M., Kang, Y.-J., et al. (2019). Engineering of Human Brain Organoids with a Functional Vascular-like System. Nat. Methods 16 (11), 1169-1175. doi:10.1038/s41592-019-0586-5

Calar, K., Plesselova, S., Bhattacharya, S., Jorgensen, M., and de la Puente, P. (2020). Human Plasma-Derived 3D Cultures Model Breast Cancer Treatment Responses and Predict Clinically Effective Drug Treatment Concentrations. Cancers 12 (7), 1722. doi:10.3390/cancers12071722

Campinoti, S., Gjinovci, A., Ragazzini, R., Zanieri, L., Ariza-McNaughton, L., Catucci, M., et al. (2020). Reconstitution of a Functional Human Thymus by Postnatal Stromal Progenitor Cells and Natural Whole-Organ Scaffolds. Nat. Commun. 11 (1), 6372. doi:10.1038/s41467-020-20082-7

Candiello, J., Grandhi, T. S. P., Goh, S. K., Vaidya, V., Lemmon-Kishi, M., Eliato, K. R., et al. (2018). 3D Heterogeneous Islet Organoid Generation from Human Embryonic Stem Cells Using a Novel Engineered Hydrogel Platform. Biomaterials 177, 27-39. doi:10.1016/j.biomaterials.2018.05.031

Capeling, M. M., Czerwinski, M., Huang, S., Tsai, Y.-H., Wu, A., Nagy, M. S., et al. (2019). Nonadhesive Alginate Hydrogels Support Growth of Pluripotent Stem Cell-Derived Intestinal Organoids. Stem Cell Rep. 12 (2), 381-394. doi:10.1016/ j.stemcr.2018.12.001

Courau, T., Bonnereau, J., Chicoteau, J., Bottois, H., Remark, R., Assante Miranda, L., et al. (2019). Cocultures of Human Colorectal Tumor Spheroids with Immune Cells Reveal the Therapeutic Potential of MICA/B and NKG2A Targeting for Cancer Treatment. J. Immunotherapy Cancer 7 (1), 74. doi:10.1186/s40425-019-0553-9

Cristobal, A., van den Toorn, H. W. P., van de Wetering, M., Clevers, H., Heck, A. J. R., and Mohammed, S. (2017). Personalized Proteome Profiles of Healthy and Tumor Human Colon Organoids Reveal Both Individual Diversity and Basic Features of Colorectal Cancer. Cell Rep. 18 (1), 263-274. doi:10.1016/ j.celrep.2016.12.016

Cruz-Acuña, R., Quirós, M., Farkas, A. E., Dedhia, P. H., Huang, S., Siuda, D., et al. (2017). Synthetic Hydrogels for Human Intestinal Organoid Generation and Colonic Wound Repair. Nat. Cell Biol 19 (11), 1326-1335. doi:10.1038/ncb3632 
Cugola, F. R., Fernandes, I. R., Russo, F. B., Freitas, B. C., Dias, J. L. M., Guimarães, K. P., et al. (2016). The Brazilian Zika Virus Strain Causes Birth Defects in Experimental Models. Nature 534 (7606), 267-271. doi:10.1038/nature18296

Cui, X., Morales, R.-T. T., Qian, W., Wang, H., Gagner, J.-P., Dolgalev, I., et al. (2018). Hacking Macrophage-Associated Immunosuppression for Regulating Glioblastoma Angiogenesis. Biomaterials 161, 164-178. doi:10.1016/ j.biomaterials.2018.01.053

Curvello, R., and Garnier, G. (2021). Cationic Cross-Linked Nanocellulose-Based Matrices for the Growth and Recovery of Intestinal Organoids. Biomacromolecules 22 (2), 701-709. doi:10.1021/acs.biomac.0c01510

Curvello, R., Kerr, G., Micati, D. J., Chan, W. H., Raghuwanshi, V. S., Rosenbluh, J., et al. (2020). Engineered Plant-Based Nanocellulose Hydrogel for Small Intestinal Organoid Growth. Adv. Sci. 8 (1), 2002135. doi:10.1002/ advs.202002135

Dekkers, J. F., Wiegerinck, C. L., de Jonge, H. R., Bronsveld, I., Janssens, H. M., de Winter-de Groot, K. M., et al. (2013). A Functional CFTR Assay Using Primary Cystic Fibrosis Intestinal Organoids. Nat. Med. 19 (7), 939-945. doi:10.1038/ nm.3201

Del Bufalo, F., Manzo, T., Hoyos, V., Yagyu, S., Caruana, I., Jacot, J., et al. (2016). 3D Modeling of Human Cancer: A PEG-Fibrin Hydrogel System to Study the Role of Tumor Microenvironment and Recapitulate the In Vivo Effect of Oncolytic Adenovirus. Biomaterials 84, 76-85. doi:10.1016/ j.biomaterials.2016.01.030

Deng, W.-L., Gao, M.-L., Lei, X.-L., Lv, J.-N., Zhao, H., He, K.-W., et al. (2018). Gene Correction Reverses Ciliopathy and Photoreceptor Loss in iPSC-Derived Retinal Organoids from Retinitis Pigmentosa Patients. Stem Cell Rep. 10 (4), 1267-1281. doi:10.1016/j.stemcr.2018.02.003

Diao, J., Liu, J., Wang, S., Chang, M., Wang, X., Guo, B., et al. (2019). Sweat Gland Organoids Contribute to Cutaneous Wound Healing and Sweat Gland Regeneration. Cell Death Dis 10 (3), 238. doi:10.1038/s41419-019-1485-5

Dijkstra, K. K., Monkhorst, K., Schipper, L. J., Hartemink, K. J., Smit, E. F., Kaing, S., et al. (2020). Challenges in Establishing Pure Lung Cancer Organoids Limit Their Utility for Personalized Medicine. Cell Rep. 31 (5), 107588. doi:10.1016/ j.celrep. 2020.107588

Drapkin, B. J., George, J., Christensen, C. L., Mino-Kenudson, M., Dries, R., Sundaresan, T., et al. (2018). Genomic and Functional Fidelity of Small Cell Lung Cancer Patient-Derived Xenografts. Cancer Discov. 8 (5), 600-615. doi:10.1158/2159-8290.CD-17-0935

Drost, J., van Boxtel, R., Blokzijl, F., Mizutani, T., Sasaki, N., Sasselli, V., et al. (2017). Use of CRISPR-Modified Human Stem Cell Organoids to Study the Origin of Mutational Signatures in Cancer. Science 358 (6360), 234-238. doi:10.1126/science.aao3130

Du, C., Narayanan, K., Leong, M. F., Ibrahim, M. S., Chua, Y. P., Khoo, V. M. H., et al. (2016). Functional Kidney Bioengineering with Pluripotent Stem-CellDerived Renal Progenitor Cells and Decellularized Kidney Scaffolds. Adv. Healthc. Mater. 5 (16), 2080-2091. doi:10.1002/adhm.201600120

Dulla, K., Aguila, M., Lane, A., Jovanovic, K., Parfitt, D. A., Schulkens, I., et al. (2018). Splice-Modulating Oligonucleotide QR-110 Restores CEP290 mRNA and Function in Human c.2991+1655A>G LCA10 Models. Mol. Ther. - Nucleic Acids 12, 730-740. doi:10.1016/j.omtn.2018.07.010

Dwyer, B. J., Macmillan, M. T., Brennan, P. N., and Forbes, S. J. (2021). Cell Therapy for Advanced Liver Diseases: Repair or Rebuild. J. Hepatol. 74 (1), 185-199. doi:10.1016/j.jhep.2020.09.014

Fan, Y., Tajima, A., Goh, S. K., Geng, X., Gualtierotti, G., Grupillo, M., et al. (2015). Bioengineering Thymus Organoids to Restore Thymic Function and Induce Donor-specific Immune Tolerance to Allografts. Mol. Ther. 23 (7), 1262-1277. doi:10.1038/mt.2015.77

Farago, A. F., Yeap, B. Y., Stanzione, M., Hung, Y. P., Heist, R. S., Marcoux, J. P., et al. (2019). Combination Olaparib and Temozolomide in Relapsed Small-Cell Lung Cancer. Cancer Discov. 9 (10), 1372-1387. doi:10.1158/2159-8290.CD-190582

Feng, R.-M., Zong, Y.-N., Cao, S.-M., and Xu, R.-H. (2019). Current Cancer Situation in China: Good or Bad News from the 2018 Global Cancer Statistics? Cancer Commun. 39 (1), 22. doi:10.1186/s40880-019-0368-6

Fong, E. L. S., Toh, T. B., Lin, Q. X. X., Liu, Z., Hooi, L., Mohd Abdul Rashid, M. B., et al. (2018). Generation of Matched Patient-Derived Xenograft In Vitro-In Vivo Models Using 3D Macroporous Hydrogels for the Study of Liver Cancer. Biomaterials 159, 229-240. doi:10.1016/j.biomaterials.2017.12.026
Forbester, J. L., Lees, E. A., Goulding, D., Forrest, S., Yeung, A., Speak, A., et al. (2018). Interleukin-22 Promotes Phagolysosomal Fusion to Induce protection againstSalmonella entericaTyphimurium in Human Epithelial Cells. Proc. Natl. Acad. Sci. USA 115 (40), 10118-10123. doi:10.1073/pnas.1811866115

Fordham, R. P., Yui, S., Hannan, N. R. F., Soendergaard, C., Madgwick, A., Schweiger, P. J., et al. (2013). Transplantation of Expanded Fetal Intestinal Progenitors Contributes to colon Regeneration after Injury. Cell Stem Cell 13 (6), 734-744. doi:10.1016/j.stem.2013.09.015

Fukuda, M., Mizutani, T., Mochizuki, W., Matsumoto, T., Nozaki, K., Sakamaki, Y., et al. (2014). Small Intestinal Stem Cell Identity Is Maintained with Functional Paneth Cells in Heterotopically Grafted Epithelium onto the colon. Genes Dev. 28 (16), 1752-1757. doi:10.1101/gad.245233.114

Gao, H., Korn, J. M., Ferretti, S., Monahan, J. E., Wang, Y., Singh, M., et al. (2015). High-throughput Screening Using Patient-Derived Tumor Xenografts to Predict Clinical Trial Drug Response. Nat. Med. 21 (11), 1318-1325. doi: $10.1038 / \mathrm{nm} .3954$

Gerbe, F., Sidot, E., Smyth, D. J., Ohmoto, M., Matsumoto, I., Dardalhon, V., et al. (2016). Intestinal Epithelial Tuft Cells Initiate Type 2 Mucosal Immunity to Helminth Parasites. Nature 529 (7585), 226-230. doi:10.1038/nature16527

Geurts, M. H., de Poel, E., Amatngalim, G. D., Oka, R., Meijers, F. M., Kruisselbrink, E., et al. (2020). CRISPR-based Adenine Editors Correct Nonsense Mutations in a Cystic Fibrosis Organoid Biobank. Cell Stem Cell 26 (4), 503-510. doi:10.1016/j.stem.2020.01.019

Giobbe, G. G., Crowley, C., Luni, C., Campinoti, S., Khedr, M., Kretzschmar, K., et al. (2019). Extracellular Matrix Hydrogel Derived from Decellularized Tissues Enables Endodermal Organoid Culture. Nat. Commun. 10 (1), 5658. doi:10.1038/s41467-019-13605-4

Gjorevski, N., and Lutolf, M. P. (2017). Synthesis and Characterization of Well-Defined Hydrogel Matrices and Their Application to Intestinal Stem Cell and Organoid Culture. Nat. Protoc. 12 (11), 2263-2274. doi:10.1038/ nprot.2017.095

Gomez-Giro, G., Arias-Fuenzalida, J., Jarazo, J., Zeuschner, D., Ali, M., Possemis, N., et al. (2019). Synapse Alterations Precede Neuronal Damage and Storage Pathology in a Human Cerebral Organoid Model of CLN3-Juvenile Neuronal Ceroid Lipofuscinosis. Acta Neuropathol. Commun. 7 (1), 222. doi:10.1186/ s40478-019-0871-7

Greten, F. R., and Grivennikov, S. I. (2019). Inflammation and Cancer: Triggers, Mechanisms, and Consequences. Immunity 51 (1), 27-41. doi:10.1016/ j.immuni.2019.06.025

Guan, Y., Xu, D., Garfin, P. M., Ehmer, U., Hurwitz, M., Enns, G., et al. (2017). Human Hepatic Organoids for the Analysis of Human Genetic Diseases. JCI Insight 2 (17). doi:10.1172/jci.insight.94954

Hai, J., Zhang, H., Zhou, J., Wu, Z., Chen, T., Papadopoulos, E., et al. (2020). Generation of Genetically Engineered Mouse Lung Organoid Models for Squamous Cell Lung Cancers Allows for the Study of Combinatorial Immunotherapy. Clin. Cancer Res. 26 (13), 3431-3442. doi:10.1158/10780432.CCR-19-1627

Ham, O., Jin, Y. B., Kim, J., and Lee, M.-O. (2020). Blood Vessel Formation in Cerebral Organoids Formed from Human Embryonic Stem Cells. Biochem. Biophysical Res. Commun. 521 (1), 84-90. doi:10.1016/j.bbrc.2019.10.079

Han, Y., Duan, X., Yang, L., Nilsson-Payant, B. E., Wang, P., Duan, F., et al. (2021). Identification of SARS-CoV-2 Inhibitors Using Lung and Colonic Organoids. Nature 589 (7841), 270-275. doi:10.1038/s41586-020-2901-9

Han, Y. L., Pegoraro, A. F., Li, H., Li, K., Yuan, Y., Xu, G., et al. (2020). Cell Swelling, Softening and Invasion in a Three-Dimensional Breast Cancer Model. Nat. Phys. 16 (1), 101-108. doi:10.1038/s41567-019-0680-8

Heo, I., Dutta, D., Schaefer, D. A., Iakobachvili, N., Artegiani, B., Sachs, N., et al. (2018). Modelling Cryptosporidium Infection in Human Small Intestinal and Lung Organoids. Nat. Microbiol. 3 (7), 814-823. doi:10.1038/s41564-0180177-8

Hernandez-Gordillo, V., Kassis, T., Lampejo, A., Choi, G., Gamboa, M. E., Gnecco, J. S., et al. (2020). Fully Synthetic Matrices for In Vitro Culture of Primary Human Intestinal Enteroids and Endometrial Organoids. Biomaterials 254, 120125. doi:10.1016/j.biomaterials.2020.120125

Holokai, L., Chakrabarti, J., Lundy, J., Croagh, D., Adhikary, P., Richards, S. S., et al. (2020). Murine- and Human-Derived Autologous Organoid/Immune Cell Cocultures as Pre-clinical Models of Pancreatic Ductal Adenocarcinoma. Cancers 12 (12), 3816. doi:10.3390/cancers12123816 
Homan, K. A., Gupta, N., Kroll, K. T., Kolesky, D. B., Skylar-Scott, M., Miyoshi, T., et al. (2019). Flow-enhanced Vascularization and Maturation of Kidney Organoids In Vitro. Nat. Methods 16 (3), 255-262. doi:10.1038/s41592-0190325-y

Howitt, M. R., Lavoie, S., Michaud, M., Blum, A. M., Tran, S. V., Weinstock, J. V., et al. (2016). Tuft Cells, Taste-Chemosensory Cells, Orchestrate Parasite Type 2 Immunity in the Gut. Science 351 (6279), 1329-1333. doi:10.1126/ science.aaf 1648

Hu, H., Gehart, H., Artegiani, B., LÖpez-Iglesias, C., Dekkers, F., Basak, O., et al. (2018). Long-Term Expansion of Functional Mouse and Human Hepatocytes as 3D Organoids. Cell 175 (6), 1591-1606. doi:10.1016/j.cell.2018.11.013

Huang, K. Y., Lin, M. S., Kuo, T. C., Chen, C. L., Lin, C. C., Chou, Y. C., et al. (2021). Humanized COVID-19 Decoy Antibody Effectively Blocks Viral Entry and Prevents SARS-CoV-2 Infection. EMBO Mol. Med. 13 (1), e12828. doi:10.15252/emmm.202012828

Huch, M., Gehart, H., van Boxtel, R., Hamer, K., Blokzijl, F., Verstegen, M. M. A., et al. (2015). Long-term Culture of Genome-Stable Bipotent Stem Cells from Adult Human Liver. Cell 160 (1-2), 299-312. doi:10.1016/j.cell.2014.11.050

Huch, M., and Koo, B.-K. (2015). Modeling Mouse and Human Development Using Organoid Cultures. Development 142 (18), 3113-3125. doi:10.1242/ dev.118570

Hun, M., Barsanti, M., Wong, K., Ramshaw, J., Werkmeister, J., and Chidgey, A. P. (2017). Native Thymic Extracellular Matrix Improves In Vivo Thymic Organoid T Cell Output, and Drives In Vitro Thymic Epithelial Cell Differentiation. Biomaterials 118, 1-15. doi:10.1016/j.biomaterials.2016.11.054

Hushka, E. A., Yavitt, F. M., Brown, T. E., Dempsey, P. J., and Anseth, K. S. (2020). Relaxation of Extracellular Matrix Forces Directs Crypt Formation and Architecture in Intestinal Organoids. Adv. Healthc. Mater. 9 (8), 1901214. doi:10.1002/adhm.201901214

Hussain, A., Voisin, V., Poon, S., Karamboulas, C., Bui, N. H. B., Meens, J., et al. (2020). Distinct Fibroblast Functional States Drive Clinical Outcomes in Ovarian Cancer and Are Regulated by TCF21. J. Exp. Med. 217 (8). doi:10.1084/jem.20191094

Iefremova, V., Manikakis, G., Krefft, O., Jabali, A., Weynans, K., Wilkens, R., et al. (2017). An Organoid-Based Model of Cortical Development Identifies Noncell-autonomous Defects in Wnt Signaling Contributing to Miller-Dieker Syndrome. Cell Rep. 19 (1), 50-59. doi:10.1016/j.celrep.2017.03.047

Ihara, S., Hirata, Y., Hikiba, Y., Yamashita, A., Tsuboi, M., Hata, M., et al. (2018). Adhesive Interactions between Mononuclear Phagocytes and Intestinal Epithelium Perturb Normal Epithelial Differentiation and Serve as a Therapeutic Target in Inflammatory Bowel Disease. J. Crohns Colitis 12 (10), 1219-1231. doi:10.1093/ecco-jcc/jjy088

Iorio, F., Knijnenburg, T. A., Vis, D. J., Bignell, G. R., Menden, M. P., Schubert, M., et al. (2016). A Landscape of Pharmacogenomic Interactions in Cancer. Cell 166 (3), 740-754. doi:10.1016/j.cell.2016.06.017

Jacob, F., Pather, S. R., Huang, W.-K., Zhang, F., Wong, S. Z. H., Zhou, H., et al. (2020). Human Pluripotent Stem Cell-Derived Neural Cells and Brain Organoids Reveal SARS-CoV-2 Neurotropism Predominates in Choroid Plexus Epithelium. Cell Stem Cell 27 (6), 937-950. doi:10.1016/ j.stem.2020.09.016

Jenkins, R. W., Aref, A. R., Lizotte, P. H., Ivanova, E., Stinson, S., Zhou, C. W., et al. (2018). Ex Vivo Profiling of PD-1 Blockade Using Organotypic Tumor Spheroids. Cancer Discov. 8 (2), 196-215. doi:10.1158/2159-8290.CD-17-0833

Jian, M., Ren, L., He, G., Lin, Q., Tang, W., Chen, Y., et al. (2020). A Novel PatientDerived Organoids-Based Xenografts Model for Preclinical Drug Response Testing in Patients with Colorectal Liver Metastases. J. Transl Med. 18 (1), 234. doi:10.1186/s12967-020-02407-8

Jowett, G. M., Norman, M. D. A., Yu, T. T. L., Rosell Arévalo, P., Hoogland, D., Lust, S. T., et al. (2021). ILC1 Drive Intestinal Epithelial and Matrix Remodelling. Nat. Mater. 20 (2), 250-259. doi:10.1038/s41563-0200783-8

Jung, D. J., Shin, T. H., Kim, M., Sung, C. O., Jang, S. J., and Jeong, G. S. (2019). A One-Stop Microfluidic-Based Lung Cancer Organoid Culture Platform for Testing Drug Sensitivity. Lab. Chip 19 (17), 2854-2865. doi:10.1039/c9lc00496c

Jung, K. B., Lee, H., Son, Y. S., Lee, M.-O., Kim, Y.-D., Oh, S. J., et al. (2018). Interleukin-2 Induces the In Vitro Maturation of Human Pluripotent Stem Cell-Derived Intestinal Organoids. Nat. Commun. 9 (1), 3039. doi:10.1038/ s41467-018-05450-8
Kim, M., Mun, H., Sung, C. O., Cho, E. J., Jeon, H.-J., Chun, S.-M., et al. (2019). Patient-derived Lung Cancer Organoids as In Vitro Cancer Models for Therapeutic Screening. Nat. Commun. 10 (1), 3991. doi:10.1038/s41467-01911867-6

Lai, Y., Wei, X., Lin, S., Qin, L., Cheng, L., and Li, P. (2017). Current Status and Perspectives of Patient-Derived Xenograft Models in Cancer Research. J. Hematol. Oncol. 10 (1), 106. doi:10.1186/s13045-017-0470-7

Lamers, M. M., Beumer, J., van der Vaart, J., Knoops, K., Puschhof, J., Breugem, T. I., et al. (2020). SARS-CoV-2 Productively Infects Human Gut Enterocytes. Science 369 (6499), 50-54. doi:10.1126/science.abc1669

Lane, A., Jovanovic, K., Shortall, C., Ottaviani, D., Panes, A. B., Schwarz, N., et al. (2020). Modeling and Rescue of RP2 Retinitis Pigmentosa Using iPSC-Derived Retinal Organoids. Stem Cell Rep. 15 (1), 67-79. doi:10.1016/ j.stemcr.2020.05.007

Lebreton, F., Lavallard, V., Bellofatto, K., Bonnet, R., Wassmer, C. H., Perez, L., et al. (2019). Insulin-producing Organoids Engineered from Islet and Amniotic Epithelial Cells to Treat Diabetes. Nat. Commun. 10 (1), 4491. doi:10.1038/ s41467-019-12472-3

Lee, J.-K., Liu, Z., Sa, J. K., Shin, S., Wang, J., Bordyuh, M., et al. (2018). Pharmacogenomic Landscape of Patient-Derived Tumor Cells Informs Precision Oncology Therapy. Nat. Genet. 50 (10), 1399-1411. doi:10.1038/ s41588-018-0209-6

Lee, S. H., Hu, W., Matulay, J. T., Silva, M. V., Owczarek, T. B., Kim, K., et al. (2018). Tumor Evolution and Drug Response in Patient-Derived Organoid Models of Bladder Cancer. Cell 173 (2), 515-528. doi:10.1016/j.cell.2018.03.017

Lei, M., Schumacher, L. J., Lai, Y.-C., Juan, W.-T., Yeh, C.-Y., Wu, P., et al. (2017). Self-organization Process in Newborn Skin Organoid Formation Inspires Strategy to Restore Hair Regeneration of Adult Cells. Proc. Natl. Acad. Sci. USA 114 (34), E7101-E7110. doi:10.1073/pnas.1700475114

Lenti, E., Bianchessi, S., Proulx, S. T., Palano, M. T., Genovese, L., Raccosta, L., et al. (2019). Therapeutic Regeneration of Lymphatic and Immune Cell Functions upon Lympho-Organoid Transplantation. Stem Cell Rep. 12 (6), 1260-1268. doi:10.1016/j.stemcr.2019.04.021

Li, X., Francies, H. E., Secrier, M., Perner, J., Miremadi, A., Galeano-Dalmau, N., et al. (2018). Organoid Cultures Recapitulate Esophageal Adenocarcinoma Heterogeneity Providing a Model for Clonality Studies and Precision Therapeutics. Nat. Commun. 9 (1), 2983. doi:10.1038/s41467-018-05190-9

Liao, L., Song, M., Li, X., Tang, L., Zhang, T., Zhang, L., et al. (2017). E3 Ubiquitin Ligase UBR5 Drives the Growth and Metastasis of Triple-Negative Breast Cancer. Cancer Res. 77 (8), 2090-2101. doi:10.1158/0008-5472.CAN-16-2409

Lieber, S. R., Schiano, T. D., and Rhodes, R. (2018). Should Living Donor Liver Transplantation Be an Option when Deceased Donation Is Not? J. Hepatol. 68 (5), 1076-1082. doi:10.1016/j.jhep.2017.10.024

Lindemans, C. A., Calafiore, M., Mertelsmann, A. M., O’Connor, M. H., Dudakov, J. A., Jenq, R. R., et al. (2015). Interleukin-22 Promotes Intestinal-Stem-CellMediated Epithelial Regeneration. Nature 528 (7583), 560-564. doi:10.1038/ nature 16460

Liu, H., Wang, Y., Cui, K., Guo, Y., Zhang, X., and Qin, J. (2019). Advances in Hydrogels in Organoids and Organs-on-a-Chip. Adv. Mater. 31 (50), 1902042. doi:10.1002/adma.201902042

Loupy, A., and Lefaucheur, C. (2018). Antibody-Mediated Rejection of SolidOrgan Allografts. N. Engl. J. Med. 379 (12), 1150-1160. doi:10.1056/ NEJMra1802677

Luo, X., Fong, E. L. S., Zhu, C., Lin, Q. X. X., Xiong, M., Li, A., et al. (2021). Hydrogel-based Colorectal Cancer Organoid Co-culture Models. Acta Biomater. 132, 461-472. doi:10.1016/j.actbio.2020.12.037

Luo, Z., Zhang, S., Pan, J., Shi, R., Liu, H., Lyu, Y., et al. (2018). Time-responsive Osteogenic Niche of Stem Cells: A Sequentially Triggered, Dual-Peptide Loaded, Alginate Hybrid System for Promoting Cell Activity and OsteoDifferentiation. Biomaterials 163, 25-42. doi:10.1016/ j.biomaterials.2018.02.025

Mahalingam, R., Dharmalingam, P., Santhanam, A., Kotla, S., Davuluri, G., Karmouty-Quintana, H., et al. (2021). Single-cell RNA Sequencing Analysis of SARS-CoV-2 Entry Receptors in Human Organoids. J. Cell Physiol 236 (4), 2950-2958. doi:10.1002/jcp.30054

Mansour, A. A., Goncalves, J. T., Gonçalves, C. W., Li, H., Fernandes, S., Quang, D., et al. (2018). An In Vivo Model of Functional and Vascularized Human Brain Organoids. Nat. Biotechnol. 36 (5), 432-441. doi:10.1038/nbt.4127 
Mariani, J., Coppola, G., Zhang, P., Abyzov, A., Provini, L., Tomasini, L., et al. (2015). FOXG1-Dependent Dysregulation of GABA/Glutamate Neuron Differentiation in Autism Spectrum Disorders. Cell 162 (2), 375-390. doi:10.1016/j.cell.2015.06.034

Maule, G., Casini, A., Montagna, C., Ramalho, A. S., De Boeck, K., Debyser, Z., et al. (2019). Allele Specific Repair of Splicing Mutations in Cystic Fibrosis through AsCas12a Genome Editing. Nat. Commun. 10 (1), 3556. doi:10.1038/s41467019-11454-9

Mazzone, M., and Bergers, G. (2019). Regulation of Blood and Lymphatic Vessels by Immune Cells in Tumors and Metastasis. Annu. Rev. Physiol. 81, 535-560. doi:10.1146/annurev-physiol-020518-114721

Meran, L., Massie, I., Campinoti, S., Weston, A. E., Gaifulina, R., Tullie, L., et al. (2020). Engineering Transplantable Jejunal Mucosal Grafts Using PatientDerived Organoids from Children with Intestinal Failure. Nat. Med. 26 (10), 1593-1601. doi:10.1038/s41591-020-1024-Z

Miura, S., and Suzuki, A. (2017). Generation of Mouse and Human OrganoidForming Intestinal Progenitor Cells by Direct Lineage Reprogramming. Cell Stem Cell 21 (4), 456-471. doi:10.1016/j.stem.2017.08.020

Mollica, P. A., Booth-Creech, E. N., Reid, J. A., Zamponi, M., Sullivan, S. M., Palmer, X.-L., et al. (2019). 3D Bioprinted Mammary Organoids and Tumoroids in Human Mammary Derived ECM Hydrogels. Acta Biomater. 95, 201-213. doi:10.1016/j.actbio.2019.06.017

Monteil, V., Dyczynski, M., Lauschke, V. M., Kwon, H., Wirnsberger, G., Youhanna, S., et al. (2021). Human Soluble ACE2 Improves the Effect of Remdesivir in SARS-CoV-2 Infection. EMBO Mol. Med. 13 (1), e13426. doi:10.15252/emmm.202013426

Monteil, V., Kwon, H., Prado, P., Hagelkrüys, A., Wimmer, R. A., Stahl, M., et al. (2020). Inhibition of SARS-CoV-2 Infections in Engineered Human Tissues Using Clinical-Grade Soluble Human ACE2. Cell 181 (4), 905-913. doi:10.1016/j.cell.2020.04.004

Moris, N., Anlas, K., van den Brink, S. C., Alemany, A., Schröder, J., Ghimire, S., et al. (2020). An In Vitro Model of Early Anteroposterior Organization during Human Development. Nature 582 (7812), 410-415. doi:10.1038/s41586-0202383-9

Muller, S., Ader, I., Creff, J., Leménager, H., Achard, P., Casteilla, L., et al. (2019). Human Adipose Stromal-Vascular Fraction Self-Organizes to Form Vascularized Adipose Tissue in 3D Cultures. Sci. Rep. 9 (1), 7250. doi:10.1038/s41598-019-43624-6

Nalbach, L., Roma, L. P., Schmitt, B. M., Becker, V., Körbel, C., Wrublewsky, S., et al. (2021). Improvement of Islet Transplantation by the Fusion of Islet Cells with Functional Blood Vessels. EMBO Mol. Med. 13 (1), e12616. doi:10.15252/ emmm.202012616

Nayak, B., Balachander, G. M., Manjunath, S., Rangarajan, A., and Chatterjee, K. (2019). Tissue Mimetic 3D Scaffold for Breast Tumor-Derived Organoid Culture toward Personalized Chemotherapy. Colloids Surf. B: Biointerfaces 180, 334-343. doi:10.1016/j.colsurfb.2019.04.056

Neal, J. T., Li, X., Zhu, J., Giangarra, V., Grzeskowiak, C. L., Ju, J., et al. (2018). Organoid Modeling of the Tumor Immune Microenvironment. Cell 175 (7), 1972-1988. doi:10.1016/j.cell.2018.11.021

Ng, S., Tan, W. J., Pek, M. M. X., Tan, M.-H., and Kurisawa, M. (2019). Mechanically and Chemically Defined Hydrogel Matrices for PatientDerived Colorectal Tumor Organoid Culture. Biomaterials 219, 119400. doi:10.1016/j.biomaterials.2019.119400

Nie, Y.-Z., Zheng, Y.-W., Miyakawa, K., Murata, S., Zhang, R.-R., Sekine, K., et al. (2018). Recapitulation of Hepatitis B Virus-Host Interactions in Liver Organoids from Human Induced Pluripotent Stem Cells. EBioMedicine 35, 114-123. doi:10.1016/j.ebiom.2018.08.014

Nozaki, K., Mochizuki, W., Matsumoto, Y., Matsumoto, T., Fukuda, M., Mizutani, T., et al. (2016). Co-culture with Intestinal Epithelial Organoids Allows Efficient Expansion and Motility Analysis of Intraepithelial Lymphocytes. J. Gastroenterol. 51 (3), 206-213. doi:10.1007/s00535-016-1170-8

Nuciforo, S., Fofana, I., Matter, M. S., Blumer, T., Calabrese, D., Boldanova, T., et al. (2018). Organoid Models of Human Liver Cancers Derived from Tumor Needle Biopsies. Cell Rep. 24 (5), 1363-1376. doi:10.1016/ j.celrep.2018.07.001

Parfitt, D. A., Lane, A., Ramsden, C. M., Carr, A.-J. F., Munro, P. M., Jovanovic, K., et al. (2016). Identification and Correction of Mechanisms Underlying
Inherited Blindness in Human iPSC-Derived Optic Cups. Cell Stem Cell 18 (6), 769-781. doi:10.1016/j.stem.2016.03.021

Pauli, C., Hopkins, B. D., Prandi, D., Shaw, R., Fedrizzi, T., Sboner, A., et al. (2017). Personalized In Vitro and In Vivo Cancer Models to Guide Precision Medicine. Cancer Discov. 7 (5), 462-477. doi:10.1158/2159-8290.CD-16-1154

Pei, R., Feng, J., Zhang, Y., Sun, H., Li, L., Yang, X., et al. (2020). Host Metabolism Dysregulation and Cell Tropism Identification in Human Airway and Alveolar Organoids upon SARS-CoV-2 Infection. Protein Cell 12, 717-733. doi:10.1007/ s13238-020-00811-w

Pham, M. T., Pollock, K. M., Rose, M. D., Cary, W. A., Stewart, H. R., Zhou, P., et al. (2018). Generation of Human Vascularized Brain Organoids. Neuroreport 29 (7), 588-593. doi:10.1097/WNR.0000000000001014

Pott, J., Kabat, A. M., and Maloy, K. J. (2018). Intestinal Epithelial Cell Autophagy Is Required to Protect against TNF-Induced Apoptosis during Chronic Colitis in Mice. Cell Host \& Microbe 23 (2), 191-202. doi:10.1016/j.chom.2017.12.017

Puca, L., Bareja, R., Prandi, D., Shaw, R., Benelli, M., Karthaus, W. R., et al. (2018). Patient Derived Organoids to Model Rare Prostate Cancer Phenotypes. Nat. Commun. 9 (1), 2404. doi:10.1038/s41467-018-04495-Z

Raikwar, S. P., Kim, E.-M., Sivitz, W. I., Allamargot, C., Thedens, D. R., and Zavazava, N. (2015). Human iPS Cell-Derived Insulin Producing Cells Form Vascularized Organoids under the Kidney Capsules of Diabetic Mice. PLoS One 10 (1), e0116582. doi:10.1371/journal.pone.0116582

Rajasekar, S., Lin, D. S. Y., Abdul, L., Liu, A., Sotra, A., Zhang, F., et al. (2020). IFlowPlate-A Customized 384-Well Plate for the Culture of Perfusable Vascularized Colon Organoids. Adv. Mater. 32 (46), 2002974. doi:10.1002/ adma.202002974

Ramani, A., Müller, L., Ostermann, P. N., Gabriel, E., Abida-Islam, P., MüllerSchiffmann, A., et al. (2020). SARS -CoV-2 Targets Neurons of 3D Human Brain Organoids. EMBO J. 39 (20), e106230. doi:10.15252/embj.2020106230

Rezaei Topraggaleh, T., Rezazadeh Valojerdi, M., Montazeri, L., and Baharvand, H. (2019). A Testis-Derived Macroporous 3D Scaffold as a Platform for the Generation of Mouse Testicular Organoids. Biomater. Sci. 7 (4), 1422-1436. doi:10.1039/c8bm01001c

Ruan, J., Hirai, H., Yang, D., Ma, L., Hou, X., Jiang, H., et al. (2019). Efficient Gene Editing at Major CFTR Mutation Loci. Mol. Ther. - Nucleic Acids 16, 73-81. doi:10.1016/j.omtn.2019.02.006

Sachs, N., Tsukamoto, Y., Kujala, P., Peters, P. J., and Clevers, H. (2017). Intestinal Epithelial Organoids Fuse to Form Self-Organizing Tubes in Floating Collagen Gels. Development 144 (6), 1107-1112. doi:10.1242/dev.143933

Sampaziotis, F., Justin, A. W., Tysoe, O. C., Sawiak, S., Godfrey, E. M., Upponi, S. S., et al. (2017). Reconstruction of the Mouse Extrahepatic Biliary Tree Using Primary Human Extrahepatic Cholangiocyte Organoids. Nat. Med. 23 (8), 954-963. doi:10.1038/nm.4360

Samuel, R. M., Majd, H., Richter, M. N., Ghazizadeh, Z., Zekavat, S. M., Navickas, A., et al. (2020). Androgen Signaling Regulates SARS-CoV-2 Receptor Levels and Is Associated with Severe COVID-19 Symptoms in Men. Cell Stem Cell 27 (6), 876-889. doi:10.1016/j.stem.2020.11.009

Sato, T., Vries, R. G., Snippert, H. J., van de Wetering, M., Barker, N., Stange, D. E., et al. (2009). Single Lgr5 Stem Cells Build Crypt-Villus Structures In Vitro without a Mesenchymal Niche. Nature 459 (7244), 262-265. doi:10.1038/ nature 07935

Savaikar, M. A., Whitehead, T., Roy, S., Strong, L., Fettig, N., Prmeau, T., et al. (2020). Preclinical PERCIST and 25\% of SUVmax Threshold: Precision Imaging of Response to Therapy in Co-clinical 18F-FDG PET Imaging of Triple-Negative Breast Cancer Patient-Derived Tumor Xenografts. J. Nucl. Med. 61 (6), 842-849. doi:10.2967/jnumed.119.234286

Schreurs, R. R. C. E., Baumdick, M. E., Sagebiel, A. F., Kaufmann, M., Mokry, M., Klarenbeek, P. L., et al. (2019). Human Fetal TNF- $\alpha$-Cytokine-Producing CD4+ Effector Memory $\mathrm{T}$ Cells Promote Intestinal Development and Mediate Inflammation Early in Life. Immunity 50 (2), 462-476. doi:10.1016/ j.immuni.2018.12.010

Schultz, M. B., Vera, D., and Sinclair, D. A. (2020). Can Artificial Intelligence Identify Effective COVID -19 Therapies? EMBO Mol. Med. 12 (8), el2817. doi:10.15252/emmm.202012817

Schwank, G., Koo, B.-K., Sasselli, V., Dekkers, J. F., Heo, I., Demircan, T., et al. (2013). Functional Repair of CFTR by CRISPR/Cas9 in Intestinal Stem Cell Organoids of Cystic Fibrosis Patients. Cell Stem Cell 13 (6), 653-658. doi:10.1016/j.stem.2013.11.002 
Seino, T., Kawasaki, S., Shimokawa, M., Tamagawa, H., Toshimitsu, K., Fujii, M., et al. (2018). Human Pancreatic Tumor Organoids Reveal Loss of Stem Cell Niche Factor Dependence during Disease Progression. Cell Stem Cell 22 (3), 454-467. doi:10.1016/j.stem.2017.12.009

Sewell-Loftin, M. K., Katz, J. B., George, S. C., and Longmore, G. D. (2020). Microstrains in the Extracellular Matrix Induce Angiogenesis. Lab. Chip 20 (15), 2776-2787. doi:10.1039/d0lc00145g

Shi, R., Radulovich, N., Ng, C., Liu, N., Notsuda, H., Cabanero, M., et al. (2020). Organoid Cultures as Preclinical Models of Non-small Cell Lung Cancer. Clin. Cancer Res. 26 (5), 1162-1174. doi:10.1158/1078-0432.CCR-19-1376

Shi, Y., Sun, L., Wang, M., Liu, J., Zhong, S., Li, R., et al. (2020). Vascularized Human Cortical Organoids (vOrganoids) Model Cortical Development In Vivo. Plos Biol. 18 (5), e3000705. doi:10.1371/journal.pbio.3000705

Shimokawa, M., Ohta, Y., Nishikori, S., Matano, M., Takano, A., Fujii, M., et al. (2017). Visualization and Targeting of LGR5+ Human colon Cancer Stem Cells. Nature 545 (7653), 187-192. doi:10.1038/nature22081

Simian, M., and Bissell, M. J. (2017). Organoids: A Historical Perspective of Thinking in Three Dimensions. J. Cell Biol 216 (1), 31-40. doi:10.1083/ jcb.201610056

Singh, D., Wang, S.-B., Xia, T., Tainsh, L., Ghiassi-Nejad, M., Xu, T., et al. (2018). A Biodegradable Scaffold Enhances Differentiation of Embryonic Stem Cells into a Thick Sheet of Retinal Cells. Biomaterials 154, 158-168. doi:10.1016/ j.biomaterials.2017.10.052

Soltanian, A., Ghezelayagh, Z., Mazidi, Z., Halvaei, M., Mardpour, S., Ashtiani, M. K., et al. (2019). Generation of Functional Human Pancreatic Organoids by Transplants of Embryonic Stem Cell Derivatives in a 3D-printed Tissue Trapper. J. Cell Physiol 234 (6), 9564-9576. doi:10.1002/jcp.27644

Sondorp, L. H. J., Ogundipe, V. M. L., Groen, A. H., Kelder, W., Kemper, A., Links, T. P., et al. (2020). Patient-Derived Papillary Thyroid Cancer Organoids for Radioactive Iodine Refractory Screening. Cancers 12 (11), 3212. doi:10.3390/ cancers 12113212

Sorrentino, G., Rezakhani, S., Yildiz, E., Nuciforo, S., Heim, M. H., Lutolf, M. P., et al. (2020). Mechano-modulatory Synthetic Niches for Liver Organoid Derivation. Nat. Commun. 11 (1), 3416. doi:10.1038/s41467-020-17161-0

Stanifer, M. L., Kee, C., Cortese, M., Zumaran, C. M., Triana, S., Mukenhirn, M., et al. (2020). Critical Role of Type III Interferon in Controlling SARS-CoV-2 Infection in Human Intestinal Epithelial Cells. Cell Rep. 32 (1), 107863. doi:10.1016/j.celrep.2020.107863

Stewart, E., Federico, S. M., Chen, X., Shelat, A. A., Bradley, C., Gordon, B., et al. (2017). Orthotopic Patient-Derived Xenografts of Paediatric Solid Tumours. Nature 549 (7670), 96-100. doi:10.1038/nature23647

Strobel, H. A., Gerton, T., and Hoying, J. B. (2021). Vascularized Adipocyte Organoid Model Using Isolated Human Microvessel Fragments. Biofabrication 13, 035022. doi:10.1088/1758-5090/abe187

Sugimoto, S., Ohta, Y., Fujii, M., Matano, M., Shimokawa, M., Nanki, K., et al. (2018). Reconstruction of the Human Colon Epithelium In Vivo. Cell Stem Cell 22 (2), 171-176. doi:10.1016/j.stem.2017.11.012

Takashima, S., Martin, M. L., Jansen, S. A., Fu, Y., Bos, J., Chandra, D., et al. (2019). T Cell-Derived Interferon- $\gamma$ Programs Stem Cell Death in ImmuneMediated Intestinal Damage. Sci. Immunol. 4 (42). doi:10.1126/ sciimmunol.aay8556

Tan, Q., Choi, K. M., Sicard, D., and Tschumperlin, D. J. (2017). Human Airway Organoid Engineering as a Step toward Lung Regeneration and Disease Modeling. Biomaterials 113, 118-132. doi:10.1016/ j.biomaterials.2016.10.046

Tang, K.-J., Constanzo, J. D., Venkateswaran, N., Melegari, M., Ilcheva, M., Morales, J. C., et al. (2016). Focal Adhesion Kinase Regulates the DNA Damage Response and its Inhibition Radiosensitizes Mutant KRAS Lung Cancer. Clin. Cancer Res. 22 (23), 5851-5863. doi:10.1158/1078-0432.CCR15-2603

Thaiss, C. A., Zmora, N., Levy, M., and Elinav, E. (2016). The Microbiome and Innate Immunity. Nature 535 (7610), 65-74. doi:10.1038/nature18847

Tian, Y. F., Ahn, H., Schneider, R. S., Yang, S. N., Roman-Gonzalez, L., Melnick, A. M., et al. (2015). Integrin-specific Hydrogels as Adaptable Tumor Organoids for Malignant $\mathrm{B}$ and $\mathrm{T}$ Cells. Biomaterials 73, 110-119. doi:10.1016/ j.biomaterials.2015.09.007

Tong, Z., Martyn, K., Yang, A., Yin, X., Mead, B. E., Joshi, N., et al. (2018). Towards a Defined ECM and Small Molecule Based Monolayer Culture System for the
Expansion of Mouse and Human Intestinal Stem Cells. Biomaterials 154, 60-73. doi:10.1016/j.biomaterials.2017.10.038

Toolan, H. W. (1953). Growth of Human Tumors in Cortisone-Treated Laboratory Animals: the Possibility of Obtaining Permanently Transplantable Human Tumors. Cancer Res. 13 (4-5), 389-394.

van den Berg, C. W., Koudijs, A., Ritsma, L., and Rabelink, T. J. (2020). In Vivo Assessment of Size-Selective Glomerular Sieving in Transplanted Human Induced Pluripotent Stem Cell-Derived Kidney Organoids. Jasn 31 (5), 921-929. doi:10.1681/ASN.2019060573

van den Berg, C. W., Ritsma, L., Avramut, M. C., Wiersma, L. E., van den Berg, B. M., Leuning, D. G., et al. (2018). Renal Subcapsular Transplantation of PSCDerived Kidney Organoids Induces Neo-Vasculogenesis and Significant Glomerular and Tubular Maturation In Vivo. Stem Cell Rep. 10 (3), 751-765. doi:10.1016/j.stemcr.2018.01.041

van de Wetering, M., Francies, H. E., Francis, J. M., Bounova, G., Iorio, F., Pronk, A., et al. (2015). Prospective Derivation of a Living Organoid Biobank of Colorectal Cancer Patients. Cell 161 (4), 933-945. doi:10.1016/j.cell.2015.03.053

Velazquez, J. J., LeGraw, R., Moghadam, F., Tan, Y., Kilbourne, J., Maggiore, J. C., et al. (2021). Gene Regulatory Network Analysis and Engineering Directs Development and Vascularization of Multilineage Human Liver Organoids. Cell Syst. 12 (1), 41-55. doi:10.1016/j.cels.2020.11.002

Verma, I. C., and Puri, R. D. (2015). Global burden of Genetic Disease and the Role of Genetic Screening. Semin. Fetal Neonatal Med. 20 (5), 354-363. doi:10.1016/ j.siny.2015.07.002

Vidović, D., Carlon, M. S., da Cunha, M. F., Dekkers, J. F., Hollenhorst, M. I., Bijvelds, M. J. C., et al. (2016). rAAV-CFTR $\Delta$ R Rescues the Cystic Fibrosis Phenotype in Human Intestinal Organoids and Cystic Fibrosis Mice. Am. J. Respir. Crit. Care Med. 193 (3), 288-298. doi:10.1164/rccm.201505-0914OC Villanueva, G., Marceniuk, G., Murphy, M. S., Walshaw, M., Cosulich, R., and Guideline, C. (2017). Diagnosis and Management of Cystic Fibrosis: Summary of NICE Guidance. BMJ 359, j4574. doi:10.1136/bmj.j4574

von Moltke, J., Ji, M., Liang, H.-E., and Locksley, R. M. (2016). Tuft-cell-derived IL25 Regulates an Intestinal ILC2-Epithelial Response Circuit. Nature 529 (7585), 221-225. doi:10.1038/nature16161

Votanopoulos, K. I., Forsythe, S., Sivakumar, H., Mazzocchi, A., Aleman, J., Miller, L., et al. (2020). Model of Patient-specific Immune-Enhanced Organoids for Immunotherapy Screening: Feasibility Study. Ann. Surg. Oncol. 27 (6), 1956-1967. doi:10.1245/s10434-019-08143-8

Vyas, D., Baptista, P. M., Brovold, M., Moran, E., Gaston, B., Booth, C., et al. (2018). Self-assembled Liver Organoids Recapitulate Hepatobiliary Organogenesis In Vitro. Hepatology 67 (2), 750-761. doi:10.1002/hep.29483

Waddell, A., Vallance, J. E., Hummel, A., Alenghat, T., and Rosen, M. J. (2019). IL33 Induces Murine Intestinal Goblet Cell Differentiation Indirectly via Innate Lymphoid Cell IL-13 Secretion. J.I. 202 (2), 598-607. doi:10.4049/ jimmunol.1800292

Wang, Y., Jiang, T., Qin, Z., Jiang, J., Wang, Q., Yang, S., et al. (2019). HER2 Exon 20 Insertions in Non-small-cell Lung Cancer Are Sensitive to the Irreversible Pan-HER Receptor Tyrosine Kinase Inhibitor Pyrotinib. Ann. Oncol. 30 (3), 447-455. doi:10.1093/annonc/mdy542

Wiersinga, W. J., Rhodes, A., Cheng, A. C., Peacock, S. J., and Prescott, H. C. (2020). Pathophysiology, Transmission, Diagnosis, and Treatment of Coronavirus Disease 2019 (COVID-19). JAMA 324 (8), 782-793. doi:10.1001/jama.2020.12839

Willemse, J., Roos, F. J. M., Voogt, I. J., Schurink, I. J., Bijvelds, M., Jonge, H. R., et al. (2021). Scaffolds Obtained from Decellularized Human Extrahepatic Bile Ducts Support Organoids to Establish Functional Biliary Tissue in a Dish. Biotechnol. Bioeng. 118 (2), 836-851. doi:10.1002/bit.27613

Wimmer, R. A., Leopoldi, A., Aichinger, M., Wick, N., Hantusch, B., Novatchkova, M., et al. (2019). Human Blood Vessel Organoids as a Model of Diabetic Vasculopathy. Nature 565 (7740), 505-510. doi:10.1038/s41586-018-0858-8

Xia, D., Ji, W., Xu, C., Lin, X., Wang, X., Xia, Y., et al. (2017). Knockout of MARCH2 Inhibits the Growth of HCT116 colon Cancer Cells by Inducing Endoplasmic Reticulum Stress. Cell Death Dis 8 (7), e2957. doi:10.1038/ cddis. 2017.347

Xia, S., Wu, M., Chen, S., Zhang, T., Ye, L., Liu, J., et al. (2020). Long Term Culture of Human Kidney Proximal Tubule Epithelial Cells Maintains Lineage Functions and Serves as an Ex Vivo Model for Coronavirus Associated Kidney Injury. Virol. Sin. 35 (3), 311-320. doi:10.1007/s12250-020-00253-y 
Xie, H., Zhang, W., Zhang, M., Akhtar, T., Li, Y., Yi, W., et al. (2020). Chromatin Accessibility Analysis Reveals Regulatory Dynamics of Developing Human Retina and hiPSC-Derived Retinal Organoids. Sci. Adv. 6 (6), eaay5247. doi:10.1126/sciadv.aay5247

Yan, H. H. N., Siu, H. C., Law, S., Ho, S. L., Yue, S. S. K., Tsui, W. Y., et al. (2018). A Comprehensive Human Gastric Cancer Organoid Biobank Captures Tumor Subtype Heterogeneity and Enables Therapeutic Screening. Cell Stem Cell 23 (6), 882-897. doi:10.1016/j.stem.2018.09.016

Yang, L., Han, Y., Nilsson-Payant, B. E., Gupta, V., Wang, P., Duan, X., et al. (2020). A Human Pluripotent Stem Cell-Based Platform to Study SARS-CoV-2 Tropism and Model Virus Infection in Human Cells and Organoids. Cell Stem Cell 27 (1), 125-136. doi:10.1016/j.stem.2020.06.015

Zhang, L., Liu, F., Weygant, N., Zhang, J., Hu, P., Qin, Z., et al. (2021). A Novel Integrated System Using Patient-Derived Glioma Cerebral Organoids and Xenografts for Disease Modeling and Drug Screening. Cancer Lett. 500, 87-97. doi:10.1016/j.canlet.2020.12.013

Zhang, Y., Tang, C., Span, P. N., Rowan, A. E., Aalders, T. W., Schalken, J. A., et al. (2020). Polyisocyanide Hydrogels as a Tunable Platform for Mammary Gland Organoid Formation. Adv. Sci. 7 (18), 2001797. doi:10.1002/advs.202001797

Zhao, B., Ni, C., Gao, R., Wang, Y., Yang, L., Wei, J., et al. (2020). Recapitulation of SARS-CoV-2 Infection and Cholangiocyte Damage with Human Liver Ductal Organoids. Protein Cell 11 (10), 771-775. doi:10.1007/s13238-020-00718-6

Zhou, J., Li, C., Liu, X., Chiu, M. C., Zhao, X., Wang, D., et al. (2020). Infection of Bat and Human Intestinal Organoids by SARS-CoV-2. Nat. Med. 26 (7), 1077-1083. doi:10.1038/s41591-020-0912-6
Zhu, Y., Zhang, Q., Shi, X., and Han, D. (2019). Hierarchical Hydrogel Composite Interfaces with Robust Mechanical Properties for Biomedical Applications. Adv. Mater. 31 (45), 1804950. doi:10.1002/adma.201804950

Ziegler, C. G. K., Allon, S. J., Nyquist, S. K., Mbano, I. M., Miao, V. N., Tzouanas, C. N., et al. (2020). SARS-CoV-2 Receptor ACE2 Is an Interferon-Stimulated Gene in Human Airway Epithelial Cells and Is Detected in Specific Cell Subsets across Tissues. Cell 181 (5), 1016-e19. doi:10.1016/j.cell.2020.04.035

Conflict of Interest: The authors declare that the research was conducted in the absence of any commercial or financial relationships that could be construed as a potential conflict of interest.

Publisher's Note: All claims expressed in this article are solely those of the authors and do not necessarily represent those of their affiliated organizations, or those of the publisher, the editors and the reviewers. Any product that may be evaluated in this article, or claim that may be made by its manufacturer, is not guaranteed or endorsed by the publisher.

Copyright (C) 2021 Huang, Huang, Tang, Chen, Huang, Liu, Huang, Ye and Jia. This is an open-access article distributed under the terms of the Creative Commons Attribution License (CC BY). The use, distribution or reproduction in other forums is permitted, provided the original author(s) and the copyright owner(s) are credited and that the original publication in this journal is cited, in accordance with accepted academic practice. No use, distribution or reproduction is permitted which does not comply with these terms. 